\title{
Innovative sales, $R \& D$ and total innovation expenditures: panel evidence on their dynamics
}

Citation for published version (APA):

Raymond, W., Mohnen, P., Palm, F. C., \& Schim van der Loeff, S. (2009). Innovative sales, R\&D and total innovation expenditures: panel evidence on their dynamics. METEOR, Maastricht University School of Business and Economics. METEOR Research Memorandum No. 028 https://doi.org/10.26481/umamet.2009028

Document status and date:

Published: 01/01/2009

DOI:

10.26481/umamet.2009028

Document Version:

Publisher's PDF, also known as Version of record

\section{Please check the document version of this publication:}

- A submitted manuscript is the version of the article upon submission and before peer-review. There can be important differences between the submitted version and the official published version of record.

People interested in the research are advised to contact the author for the final version of the publication, or visit the DOI to the publisher's website.

- The final author version and the galley proof are versions of the publication after peer review.

- The final published version features the final layout of the paper including the volume, issue and page numbers.

Link to publication

\footnotetext{
General rights rights.

- You may freely distribute the URL identifying the publication in the public portal. please follow below link for the End User Agreement:

www.umlib.nl/taverne-license

Take down policy

If you believe that this document breaches copyright please contact us at:

repository@maastrichtuniversity.nl

providing details and we will investigate your claim.
}

Copyright and moral rights for the publications made accessible in the public portal are retained by the authors and/or other copyright owners and it is a condition of accessing publications that users recognise and abide by the legal requirements associated with these

- Users may download and print one copy of any publication from the public portal for the purpose of private study or research.

- You may not further distribute the material or use it for any profit-making activity or commercial gain

If the publication is distributed under the terms of Article $25 \mathrm{fa}$ of the Dutch Copyright Act, indicated by the "Taverne" license above, 


\section{Maastricht University}

Wladimir Raymond, Pierre Mohnen, Franz Palm, Sybrand Schim van der Loeff

I nnovative Sales, R\&D and Total I nnovation Expenditures: Panel Evidence on their Dynamics

$\mathrm{RM} / 09 / 028$

\section{METEOR}

Faculty of Economics and Business Administration Maastricht Research School of Economics

of Technology and Organization

\section{P.O. Box 616}

NL - 6200 MD Maastricht

The Netherlands 


\title{
Innovative Sales, R\&D and Total Innovation Expenditures:
}

\section{Panel Evidence on their Dynamics}

Wladimir Raymond, Pierre Mohnen, Franz Palm and Sybrand Schim van der Loeff ${ }^{1}$

June 29, 2009

\begin{abstract}
This paper studies the dynamic relationship between input and output of innovation in Dutch manufacturing using an unbalanced panel of enterprise data from five waves of the Community Innovation Survey during 1994-2004. We estimate by maximum likelihood a dynamic panel data bivariate tobit with double-index sample selection accounting for individual effects. We find persistence of innovation input and innovation output, a lag effect of the former on the latter and a feedback effect of the latter on the former. The lag effect remains significant in the high-tech sector even after four years. Firm and industry effects are also important.
\end{abstract}

\footnotetext{
${ }^{1}$ The empirical part of this study has been carried out using the remote access facility of the Centre for Research of Economic Microdata of Statistics Netherlands. The authors wish to thank Statistics Netherlands for helping them in accessing and using the Micronoom data set. The views expressed in this paper are solely those of the authors. The first author acknowledges financial support from METEOR. The first and third author acknowledge financial support by the Royal Netherlands Academy of Arts and Sciences (KNAW). Please address correspondence to: Franz Palm, University of Maastricht, P.O. Box 616, 6200 MD Maastricht, The Netherlands; Tel.: (+31) 43388 3833; Fax: (+31) 43388 4874; f.palm@maastrichtuniversity.nl.
} 


\section{Introduction}

Starting with the pioneering work of Scherer (1965) and Schmookler (1966), an interest developed in estimating the productivity of $R \& D$ in terms of patents, what came to be known as a knowledge production function $(\mathrm{KPF})$. As the transformation from $\mathrm{R} \& \mathrm{D}$ to patents was supposed to take some time, lags were allowed in the relationship between input and output in the production of knowledge, but little evidence beyond a contemporaneous relationship was obtained. As Griliches (1990) argues, patents are taken out early in the life of a research project, when development expenditures may not yet have been completed.

In the last two decades innovation surveys were conducted in many countries offering a new measure of innovation input, namely total innovation expenditures, and a new measure of innovation output, namely the share in total sales due to new products. Total innovation expenditures encompass, besides internal and external R\&D, other costs incurred when innovating such as training costs, market research, marketing activities, the purchase of licenses, capital expenditures for innovation, and design. A product or service is regarded as new or significantly improved as regards its technical specifications, inherent characteristics, incorporated components, intended uses or user friendliness. Whereas granted patents are a scientific measure of output, measuring the recognition by some technical experts of sufficiently novel inventions, the share in total sales due to new products measures the success in introducing new products or services on the market.

This paper reexamines the dynamic relationship between innovation input and innovation output using these new measures of innovation and accounting for unobserved heterogeneity and the specificities of these data, in particular the issues of selectivity and endogeneity. The following questions will be investigated. How much time does it take between an investment in innovation and the appearance of a new product on the market (we shall compare the dynamics obtained with the traditional measure of $R \& D$ and the new measure of innovation expenditures)? Is there persistence in innovation in the sense that current innovation (be it on the input or on the output side) depends on past innovation? Does past innovation success Granger-cause future innovation efforts?

If patents are used as a strategy to appropriate the benefits from $R \& D$, we expect new firms to patent their new products or services before putting them on the market and hence a longer lag between $R \& D$ and the appearance of a new product or service on the market than between $R \& D$ and the granting of a patent. If, on the other hand, first-to-market is favored as a strategy of appropriation, then lags will be longer for patents than for new products on the market (for a discussion of appropriation strategies, see Levin et al., 1987). The introduction of a product on 
the market may also be retarded because of regulations. For instance, a successful new drug has to undergo a series of clinical trials that can take up to 10 years before the drug gets the green light from the health authorities to be put on the market.

Since in most countries, these surveys are conducted every four years, few studies have so far addressed these issues for lack of longitudinal data. In the Netherlands innovation surveys are conducted every two years. If we exclude the first survey that, like in most other countries, was exploratory and therefore less comparable to the subsequent surveys, we have 5 waves of innovation surveys available in the Netherlands. Ideally, we would like to answer these questions using project level data. Unfortunately, the innovation survey data are firm specific. Whatever dynamic relationship between inputs and outputs of innovation we can find is therefore to be seen as an average over various projects conducted by various types of firm. As much as possible we shall control for observable firm heterogeneities, but we cannot control for differences in project characteristics.

The remainder of the paper is organized as follows. We review the literature in Section 2, describe the data in Section 3, present the model in Section 4 and its estimation in Section 5. In Section 6 we discuss the results, and in Section 7 we summarize and conclude.

\section{A quick review of the literature}

We analyze jointly the effect of past innovation input on innovation output, the feedback effect of innovation output on innovation input, and the persistence of innovation input and innovation output. This section reviews what we know so far about these three issues from existing empirical work.

A panel data analysis of the knowledge production function was pioneered by Pakes and Griliches (1980) who defined a theoretical model relating innovation input to innovation output and derived a distributed lag regression where the number of patents (innovation output) was regressed on current and five lags of R\&D (innovation input) and firm individual effects. In their specification they ignored the discreteness of the patent data and used the 'within' estimator to account for individual effects. They found simultaneity between innovation input and innovation output in the sense that current $R \& D$ affects positively and significantly patents, and a lag truncation, i.e. the coefficient of the last lag but no other coefficient between the current and the last lagged R\&D was significant. Pointing out the limitations of the study of Pakes and Griliches (1980), Hausman et al. (1984) proposed several panel data models to estimate the patents-R\&D relationship that took into account the discreteness of the patents, namely fixed- and random-effects Poisson and 
negative binomial (NegBin) regressions. Using similar data to Pakes and Griliches (1980), they found that whenever the individual effects are allowed to be correlated with $R \& D$ there is only evidence of simultaneity between $R \& D$ and patents, in particular no lag effect of $R \& D$ on patents can be ascertained. This result was confirmed in the study of Hall et al. (1986) who used similar data, albeit for a larger number of firms over a smaller period, to estimate fixed-effects Poisson, NegBin and GMT Poisson regressions. ${ }^{2}$

A reverse Granger-causality from patents to R\&D was suggested by Pakes (1985) on the grounds that patents could contain information on technological opportunity that would lead to R\&D in the future. Neither Pakes (1985) nor Hall et al. (1986), however, found evidence of causality in this direction. Using two successive four-year apart innovation survey data, van Ophem et al. (2002), however, find little evidence of a Granger-causality from R\&D to patents but clear-cut evidence of a causality in the opposite direction. One additional patent increases R\&D four years down the road by $7.5 \%$.

Most empirical studies that investigate the persistence of innovation are based on patent data. With one exception, all these studies conclude, regardless of the model and estimation technique used, that there is no clear-cut evidence of a strong persistence in innovation activities (see Peters (2009) and Raymond et al. (forthcoming) for reviews of these studies). It could be argued, however, that the use of patent data is too demanding to show up any persistence, because persistence in patenting amounts to persistence in "winning the patent race", which is even harder than coming up with a new product. With innovation survey data it is possible to investigate the persistence of innovation using qualitative measures of innovation input or innovation output. Peters (2009) finds strong persistence in innovation input, in terms of $R \& D$ or non- $R \& D$ innovation expenditures, as well as on the output side, i.e. in terms of the introduction of a new product or a new process on the market. Peters (2007) concludes that success breeds success in the sense that the past share of innovative sales influences positively the future probability of innovating as well as the future share of innovative sales. Raymond et al. (forthcoming) find persistence in the probability to innovate as well as in the share of innovative sales but only in the high-tech industry. One should, however, mention that these studies only examine the introduction of products new to the firm and not major innovations. The Geroski et al. (1997) study, which examined only major innovations, did not find any persistence.

No study based on innovation survey data has so far, to our knowledge, examined the dynamic feedback effects from the share of innovative sales to R\&D or total innovation expenditures, while

\footnotetext{
${ }^{2}$ We call a GMT Poisson regression, in reference to Gouriéroux-Montfort-Trognon, a Poisson regression that is estimated using a quasi-generalized pseudo maximum likelihood method devised by the authors (see Gouriéroux et al., 1984).
} 
very few syudies have examined the opposite effects. Indirect evidence of a lag structure between $\mathrm{R} \& \mathrm{D}$ and innovative sales is provided by some past studies on the productivity effects of $\mathrm{R} \& \mathrm{D}$. Ravenscraft and Scherer (1982) mention from survey responses that $45 \%$ of the companies reported a typical time lag between the beginning of development and the first introduction of a new product of one to two years, $40 \%$ a lag of two to five years and $5 \%$ a lag of more than 5 years. From their econometric analysis they conclude to a bell-shaped lag structure with a mean lag of 4 to 6 years. Pakes and Schankerman (1984) derive a gestation lag between the R\&D outlay and its first revenues in the range of 1.2 to 2.5 years. Seldon (1987) obtains for the U.S. softwood plywood industry a best-fitting lag between public R\&D expenditures and industry output of two years. Griliches and Mairesse (1984) also report a sharp drop in the lag effect of R\&D on output after two years.

\section{Data}

The data are collected by the Centraal Bureau voor de Statistiek (CBS) and stem from five waves of the Dutch CIS, namely CIS 2 (1994-1996), CIS 2.5 (1996-1998), CIS 3 (1998-2000), CIS 3.5 (2000-2002) and CIS 4 (2002-2004), merged with data from the Production Survey (PS). Only enterprises in Dutch manufacturing (SBI 15.1-37.2) are included in the analysis. ${ }^{3}$ We consider enterprises with at least ten employees and positive sales at the end of each period covered by the innovation survey. Furthermore, we remove from the sample enterprises whose total innovation expenditures count for more than $50 \%$ of total sales.

The CIS and PS data are collected at the enterprise level. A combination of a census and a stratified random sampling is used for each wave of the CIS and PS. A census is used for the population of enterprises with at least 50 employees, and a stratified random sampling is used for enterprises with less than 50 employees. The stratum variables are the economic activity and the number of employees of an enterprise. The same cut-off point of 50 employees is applied to each wave of the CIS and PS resulting in about 3000 enterprises in each wave of the merged data of our sample.

In the CIS questionnaire, enterprises are first asked some general questions about their identity, economic activity, exports, total sales, number of employees and whether they belong to a group. Then come three crucial questions regarding 1) whether an enterprise has introduced new or improved products into the market 2) whether it has introduced new or improved processes and 3) whether it has ongoing or abandoned innovation activities during the period under review. If an enterprise answers "yes" to either of these three questions, then it has to fill out the whole

\footnotetext{
${ }^{3} \mathrm{SBI}$ stands for the Dutch standard industrial classification and is based on economic activity.
} 
questionnaire where information on innovation expenditures, sources and effects of innovation as well as innovation cooperation has to be provided. An innovative enterprise is defined as one that answers "yes" to at least one of the above-mentioned questions and reports a positive value of total innovation expenditures at the end of the period under review. ${ }^{4}$ If an enterprise answers "no" to all three questions, then only the general questions have to be answered, and any information on innovation expenditures, information sources, effects, and cooperation is missing. In order to cope with this feature of the data, we estimate a sample selection model where we correct for the bias that occurs if the analysis is restricted to the sub-sample of enterprises for which we have a complete set of data.

\subsection{Patterns}

Table 1 shows the patterns of appearance of enterprises in the unbalanced panel for which the dynamics of innovation can be potentially studied, i.e. that are present in at least two consecutive waves. ${ }^{5}$ There are 3144 such enterprises for which we provide descriptive statistics regarding size (number of employees), market share (defined as the ratio of the sales of an enterprise over the total sales of the 3-digit industry it belongs to in the Eurostat (1992) industry classification, ${ }^{6}$ and the proportion of occasionally- and continuously-innovative enterprises where a continuously-innovative (as opposed to an occasionally-innovative) enterprise is defined as one that was innovative in at least two consecutive waves between 1994 and 2004. For instance, the first pattern consists of 632 enterprises (20\% of the unbalanced panel) that were sampled only over the periods 1994-1996 and 1996-1998. These enterprises had on average 145 employees (a median of 35 employees) and an average market share of $0.25 \%$ (a median of $0.04 \%$ ) over 1994-1998; $67 \%$ of them had some innovation activities in either period and $26 \%$ had continuous innovation activities, i.e. they were innovative over the whole period 1994-1998. The second pattern represents a balanced panel of 338 enterprises that were sampled from 1994 till 2004. It accounts only for $11 \%$ of the total unbalanced panel and consists of a significantly larger proportion of continuously-innovative enterprises that

\footnotetext{
${ }^{4}$ In addition to R\&D, innovation expenditures comprise the purchase of rights and licenses to use external technology, the purchase of advanced machinery and computer hardware devoted to the implementation of product and process innovations, expenditures for technical preparations to realize the actual implementation of product and process innovations, expenditures for marketing activities aimed at market introduction of product innovations, and expenditures for staff training aimed at the development and/or introduction of a new product or process. Only indicators of the last three components of innovation expenditures are provided in CIS 4 . As a result, being innovative is based on the sum of all six continuous measures of innovation expenditures in CIS 2-CIS 3.5, and on the sum of R\&D and the first two components and on the indicators of the last three components in CIS 4 . Furthermore, the continuous measure of total innovation expenditures in this analysis consist of R\&D and the first two components.

${ }^{5}$ The sample of enterprises that take part in at least two consecutive waves of the Dutch CIS is called the "feasible" sample.

${ }^{6}$ Total sales of a 3-digit industry is obtained by adding up the sales of all the firms in our sample that belong to that industry after multiplying them by the appropriate raising factor.
} 
had on average a significantly larger market share. Hence, restricting the analysis to the sole balanced panel would miss a lot of information out of the unbalanced panel, and would yield results that are biased towards continuously-innovative enterprises with a large market share. A result of the table that is worth mentioning is the decrease in the proportion of occasional and continuously-innovative enterprises as time passes coupled with an increase in the average market share. For instance, comparing the patterns of enterprises that took part in only two waves of the CIS, we observe a decrease in the proportion of occasionally and continuously-innovative enterprises from $67 \%$ and $26 \%$ respectively in the period $1994-1998$ to $48 \%$ and $17 \%$ in the period $2000-2004$, while at the same time market share increases on average from $0.25 \%$ to $0.40 \%$. This seems to indicate that as time passes a small core of innovative enterprises emerge and hold a significantly larger market share.

Table 1: Size, market share and the proportion of innovative enterprises in each pattern of the unbalanced data for Dutch manufacturing: CIS 2, CIS 2.5, CIS 3, CIS 3.5 and CIS 4

\begin{tabular}{|c|c|c|c|c|c|c|c|c|}
\hline \multirow[t]{2}{*}{ Pattern } & \multirow[t]{2}{*}{ \# firms } & \multirow[t]{2}{*}{$\%$} & \multicolumn{2}{|c|}{ Size } & \multicolumn{2}{|c|}{ Market share $^{\dagger}(\%)$} & \multicolumn{2}{|c|}{ Innovative } \\
\hline & & & Mean & Median & Mean & Median & Occasional & Continuous $^{\dagger}$ \\
\hline 11000 & 632 & 20.10 & 145 & 35 & 0.247 & 0.035 & 0.668 & 0.261 \\
\hline 11111 & 338 & 10.75 & 263 & 119 & 0.706 & 0.126 & 0.758 & 0.536 \\
\hline 00011 & 298 & 9.48 & 187 & 50 & 0.396 & 0.038 & 0.478 & 0.168 \\
\hline 11110 & 245 & 7.79 & 161 & 75 & 0.419 & 0.071 & 0.691 & 0.443 \\
\hline 11100 & 231 & 7.35 & 160 & 70 & 0.297 & 0.071 & 0.732 & 0.407 \\
\hline 00110 & 184 & 5.85 & 81 & 48 & 0.166 & 0.032 & 0.563 & 0.220 \\
\hline 00111 & 153 & 4.87 & 364 & 115 & 0.493 & 0.065 & 0.588 & 0.294 \\
\hline 01100 & 145 & 4.61 & 126 & 50 & 0.445 & 0.037 & 0.617 & 0.228 \\
\hline 11010 & 133 & 4.23 & 84 & 60 & 0.305 & 0.051 & 0.689 & 0.218 \\
\hline 11011 & 115 & 3.66 & 189 & 110 & 0.518 & 0.119 & 0.722 & 0.322 \\
\hline 11001 & 110 & 3.50 & 116 & 45 & 0.339 & 0.059 & 0.715 & 0.203 \\
\hline 01111 & 107 & 3.40 & 332 & 102 & 0.557 & 0.109 & 0.666 & 0.418 \\
\hline 01110 & 102 & 3.24 & 127 & 74 & 0.318 & 0.064 & 0.637 & 0.346 \\
\hline 01011 & 76 & 2.42 & 326 & 71 & 0.455 & 0.069 & 0.684 & 0.158 \\
\hline 10111 & 70 & 2.23 & 157 & 121 & 0.362 & 0.107 & 0.689 & 0.289 \\
\hline 10110 & 59 & 1.88 & 126 & 70 & 0.552 & 0.071 & 0.644 & 0.181 \\
\hline 11101 & 58 & 1.84 & 174 & 93 & 0.337 & 0.120 & 0.716 & 0.323 \\
\hline 10011 & 50 & 1.59 & 159 & 106 & 0.527 & 0.104 & 0.713 & 0.180 \\
\hline 01101 & 38 & 1.21 & 186 & 76 & 0.432 & 0.074 & 0.711 & 0.228 \\
\hline Total & 3144 & 100.00 & 191 & 75 & 0.433 & 0.072 & 0.677 & 0.339 \\
\hline
\end{tabular}

$\dagger_{\text {in }}$ the domestic market. ${ }^{\ddagger}$ A continuously-innovative enterprise is one that has innovation activities in at least two successive waves of the CIS.

Table 2 shows the proportion of non-innovative, occasionally- and continuously-innovative enterprises of the feasible sample. For instance $20 \%$ of the enterprises in the sample have no innovation activities neither in period $t$ - 1 nor in period $t, 14 \%$ have innovation activities in period $t-1$ but none in period $t$, and $10 \%$ have no innovation activities in period $t-1$ but have innovation activities in period $t$. Neither of these three types of enterprises can be included in the dynamic analysis of innovation. Indeed, a complete set of data is available only for innovative enterprises and the 
dynamic analysis requires a complete set of data in at least two consecutive periods. Consequently, we have a complete set of data to study the dynamics of innovation for less than $60 \%$ of the feasible sample. Carrying out the analysis using the sub-sample of continuously-innovative firms is likely to suffer from sample selection bias. We correct for this bias by using a double index sample selection model as will be explained in Section 4 .

\begin{tabular}{|c|c|c|c|c|c|c|}
\hline \multirow{3}{*}{ Period t-1 } & \multicolumn{6}{|c|}{ Period $\mathrm{t}$} \\
\hline & \multicolumn{2}{|c|}{ Non-innovative } & \multicolumn{2}{|c|}{ Innovative } & \multicolumn{2}{|c|}{ Total $\longrightarrow$} \\
\hline & \# obs. & $\%$ & \# obs. & $\%$ & \# obs. & $\%$ \\
\hline Non-innovative & 1100 & 19.674 & 538 & 9.622 & 1638 & 29.297 \\
\hline Innovative & 756 & 13.522 & 3197 & 57.181 & 3953 & 70.703 \\
\hline Total $\downarrow$ & 1856 & 33.196 & 3735 & 66.803 & 5591 & 100.000 \\
\hline
\end{tabular}

\subsection{Dependent variables}

We are interested in explaining innovation input and innovation output. Innovation input can be measured either by the ratio of total (intramural and extramural) R\&D expenditures over total sales or the ratio of total innovation expenditures over total sales. Innovation output is measured by the share in total sales accounted for by sales of new or improved products. R\&D, total innovation expenditures and the share of innovative sales stem from the CIS, and total sales stem from the PS. Both innovation input variables and innovation output are measured for the last year of the period under review and are logit transformed in the estimation of the model so as to make them lie within the set of real numbers. ${ }^{7}$

\begin{tabular}{lccccccc}
\multicolumn{3}{c}{ Table 3: Innovation input and innovation output of continuously-innovative enterprises } \\
\hline \hline Variable & \multicolumn{7}{c}{ Statistics ${ }^{\ddagger}$} \\
\cline { 2 - 8 } & Mean & Std. Dev. & $\mathrm{P}_{10}$ & $\mathrm{P}_{18}$ & $\mathrm{Q}_{1}$ & Median & $\mathrm{Q}_{3}$ \\
\hline R\&D expenditures/sales & 0.022 & 0.041 & 0.000 & 0.001 & 0.002 & 0.008 & 0.023 \\
Total innov. expenditures/sales & 0.032 & 0.051 & 0.002 & 0.004 & 0.006 & 0.015 & 0.036 \\
Share of innovative sales & 0.240 & 0.242 & 0.000 & 0.000 & 0.050 & 0.200 & 0.350 \\
\hline${ }^{\ddagger} \mathrm{P}_{10}, \mathrm{P}_{18}, \mathrm{Q}_{1}$ and $\mathrm{Q}_{3}$ denote the $10^{\text {th }}$ and $18^{\text {th }}$ percentiles, and the first and the third quartiles \\
respectively.
\end{tabular}

Table 3 shows descriptive statistics of the variables of interest for continuously-innovative enterprises. It suggests that the first decile of these enterprises have no R\&D expenditures and have total innovation expenditures less than or equal to $0.2 \%$, while $18 \%$ are not successful in

\footnotetext{
${ }^{7}$ Innovation input and innovation output may take the value 0 , and innovation output may take the value 1 . For instance, among the continuously-innovative enterprises are non-product innovators and newly-established product innovators. The share of innovative sales takes on the value 0 for the former and 1 for the latter. We replace the zeros by some $\epsilon_{1}$ between 0 and the lowest positive value of the corresponding variable, and the ones by some $\epsilon_{2}$ between the largest value (smaller than 1 ) of the variable and 1 .
} 
achieving product innovations. The mean and median figures of innovation input are rather small and the third quartile of the continuously-innovative enterprises have $R \& D$ or total innovation expenditures over sales no larger than $4 \%$. Similarly, the mean and median share of innovative sales is about 0.20 and the third quartile of the continuously-innovative enterprises have a share of innovative sales no greater than 0.35 . The zero and small values of the variables of interest for a significant proportion of the continuously-innovative enterprises condition the choice of the empirical model. These values can be seen as inducing measurement errors which are to be explicitly controlled for. ${ }^{8}$ We deal with this by using tobit-type models which censor these zero and small values and hence lessen their influence in the model. For instance, if we used a type 1 tobit (according to Amemiya's (1984) terminology) to model separately R\&D input and innovation output with a censoring threshold ( $c_{1}$ and $c_{2}$ respectively) equal to $0,10 \%$ and $18 \%$ of the sample of continuously-innovative enterprises would be censored. Table 4 shows the distribution of the four types of continuously-innovative enterprises regarding censoring of innovation input and innovation output for both measures of innovation input and for different censoring thresholds. For instance, $4 \%$ of the sample of continuously-innovative enterprises are neither R\&D performers nor product innovators, $14 \%$ perform R\&D but are not successful in achieving product innovations, $6 \%$ do not perform R\&D but are somehow successful in achieving product innovations, and $75 \%$ perform R\&D and are successful in achieving product innovations.

\begin{tabular}{|c|c|c|c|c|}
\hline \multirow[t]{3}{*}{ (Input, Output) } & \multicolumn{2}{|c|}{ R\&D expenditures/sales } & \multicolumn{2}{|c|}{ Total innov. expenditures/sales } \\
\hline & \# obsv. & $\%$ & \# obsv. & $\%$ \\
\hline & \multicolumn{4}{|c|}{$c_{1}=0, c_{2}=0$} \\
\hline$\left(\leq c_{1}, \leq c_{2}\right)$ & 140 & 4.379 & 21 & 0.657 \\
\hline$\left(>c_{1}, \leq c_{2}\right)$ & 457 & 14.295 & 576 & 18.017 \\
\hline$\left(\leq c_{1},>c_{2}\right)$ & 193 & 6.037 & 52 & 1.627 \\
\hline$\left(>c_{1},>c_{2}\right)$ & 2407 & 75.289 & 2548 & 79.700 \\
\hline & \multicolumn{4}{|c|}{$c_{1}=0.002, c_{2}=0.05$} \\
\hline$\left(\leq c_{1}, \leq c_{2}\right)$ & 332 & 10.385 & 140 & 4.379 \\
\hline$\left(>c_{1}, \leq c_{2}\right)$ & 473 & 14.795 & 665 & 20.800 \\
\hline$\left(\leq c_{1},>c_{2}\right)$ & 468 & 14.639 & 224 & 7.007 \\
\hline$\left(>c_{1},>c_{2}\right)$ & 1924 & 60.181 & 2168 & 67.814 \\
\hline & \multicolumn{4}{|c|}{$c_{1}=0.05, c_{2}=0.002$} \\
\hline$\left(\leq c_{1}, \leq c_{2}\right)$ & 576 & 18.017 & 523 & 16.359 \\
\hline$\left(>c_{1}, \leq c_{2}\right)$ & 33 & 1.032 & 86 & 2.690 \\
\hline$\left(\leq c_{1},>c_{2}\right)$ & 2278 & 71.254 & 2108 & 65.937 \\
\hline$\left(>c_{1},>c_{2}\right)$ & 310 & 9.697 & 480 & 15.014 \\
\hline & \multicolumn{4}{|c|}{$c_{1}=0.05, c_{2}=0.05$} \\
\hline$\left(\leq c_{1}, \leq c_{2}\right)$ & 763 & 23.866 & 698 & 21.833 \\
\hline$\left(>c_{1}, \leq c_{2}\right)$ & 42 & 1.314 & 107 & 3.347 \\
\hline$\left(\leq c_{1},>c_{2}\right)$ & 2091 & 65.405 & 1933 & 60.463 \\
\hline$\left(>c_{1},>c_{2}\right)$ & 301 & 9.415 & 459 & 14.357 \\
\hline
\end{tabular}

\footnotetext{
${ }^{8} \mathrm{As}$ a matter of fact, we have in earlier stages of the analysis estimated a panel VAR model that ignores this issue and encountered problems of convergence. This is explained in detail later in the analysis.
} 
Since we control for sample selection bias, an additional dependent variable has to be considered. This variable is binary indicating whether an enterprise has been innovative. The selection rule is based on time-varying double indices, hence the dependent variable has to be considered at two consecutive periods $t-1$ and $t$.

\subsection{Explanatory variables}

We explain current innovation input and current innovation output by their lagged counterparts, ${ }^{9}$ size, market share, and indicators of cooperation, sources of information for innovation and effects of innovation. We also include as regressors three dummy variables indicating the industry the enterprise belongs to according to the OECD (2007) technology-based classification (see Appendix A) where the low-tech industry is the reference, and we control for three time dummy variables where the period 2002-2004 is the reference.

Size and market share are included as determinants of innovation in the Schumpeterian tradition (Schumpeter, 1934; 1942) where firm size and market share are expected to have an impact on both the amount of innovational effort and innovational success (see Kamien and Schwartz, 1975; Acs and Audretsch, 1987). As mentioned earlier, size is measured by the number of employees, and domestic market share is defined as the ratio of the sales of an enterprise over the total sales of the 3-digit industry it belongs to. The number of employees and sales stem from the PS and are measured for the last year of the period under review. Size and domestic market share are log-transformed in the estimation.

Enterprises that undertake innovative activities in cooperation are expected to benefit from knowledge spillovers, hence to perform better technologically (D'Aspremont and Jacquemin, 1988). The dummy variable for cooperation indicating whether an enterprise undertakes its innovative activities in cooperation during the period under review is directly reported in the CIS.

The CIS data also provide information regarding the importance of information sources of innovation on a 0-3 Likert scale. Three dummy variables of internal sources (from the enterprise or the enterprise group), institutional sources (from universities, public or private research institutes) and market sources (from customers, competitors or suppliers) are constructed as taking the value one if the corresponding information sources are deemed very important (i.e. take value 3), and zero otherwise. Similarly, the CIS data provide information regarding the importance of innovation effects on a 0-3 Likert scale. Three dummy variables of product-oriented effects (i.e. increase the range of goods, improve their quality, increase market share or enter new markets), process-oriented

\footnotetext{
${ }^{9}$ It is to be noted that a one period lag actually corresponds to two years (since the Dutch CIS is held on a bi-annual term).
} 
effects (i.e. improve flexibility of production, increase its capacity or reduce labor costs, materials or energy per unit output), and environment-oriented effects (i.e. reduce environmental impacts) are constructed as taking the value one if the corresponding effects of innovation are deemed very important (i.e. take value 3), and zero otherwise. We use the lagged values of the dummy variables for the effects of innovation to explain innovation input and innovation output.

Finally, we explain the probability that an enterprise is continuously innovative (selection equation) by its size, its market share and a dummy variable, directly reported in the CIS, for being part of a group as defined in the Oslo manual (OECD, 2005). We also include dummy variables for time and categories of industry. These variables are the few ones that are available for both innovative and non-innovative enterprises, given the design of the CIS.

Table 5: Descriptive statistics of the explanatory variables for the feasible sample and for continuously-innovative

\begin{tabular}{|c|c|c|c|c|}
\hline \multirow[t]{2}{*}{ Variable } & Mean & Std. Dev. & Mean & Std. Dev. \\
\hline & \multicolumn{2}{|c|}{ All enterprises } & \multicolumn{2}{|c|}{ Continuously innovative } \\
\hline Size & 208.511 & 782.143 & 257.930 & 897.512 \\
\hline Market share (\%) & 0.480 & 1.762 & 0.667 & 2.131 \\
\hline Part of a group & 0.725 & - & 0.781 & - \\
\hline Cooperation & - & - & 0.406 & - \\
\hline \multicolumn{5}{|l|}{ Information sources } \\
\hline Internal sources & - & - & 0.524 & - \\
\hline Market sources & - & - & 0.347 & - \\
\hline Institutional sources & - & - & 0.055 & - \\
\hline Effects of innovation & - & - & & \\
\hline Product-oriented & - & - & 0.673 & - \\
\hline Process-oriented & - & - & 0.369 & - \\
\hline Environment-oriented & - & - & 0.220 & - \\
\hline \# observations & \multicolumn{2}{|c|}{5591} & \multicolumn{2}{|c|}{3197} \\
\hline
\end{tabular}

Table 5 shows descriptive statistics of the explanatory variables for all firms and continuouslyinnovative firms of the feasible sample. The table suggests that continuously-innovative firms have on average a significantly larger market share than all firms, and that a significantly larger proportion of continuously-innovative firms is part of a group. Furthermore, only about $41 \%$ of the continuously-innovative enterprises have innovation cooperation. A significantly larger percentage of them consider internal sources as the most important sources of innovation and product-oriented effects as the most important effects of innovation.

\section{Model}

The model consists of two parts, namely a selection equation based on two indices explaining the probability of being continuously innovative and a dynamic bivariate tobit regression that explains innovation input and innovation output given continuously-innovative enterprises. The dynamics 
of innovation that we study includes the persistence of innovation input and innovation output, the lag effect of innovation input on innovation output and the feedback effect of innovation output on innovation input. As we explained earlier, we consider a selection rule based on two indices in order to correct for sample selection bias that occurs because the dynamics of innovation can be studied only for enterprises that are innovative in (at least) two consecutive periods. ${ }^{10}$

\subsection{Double index selection}

Let $d_{i t}^{*}$ be a latent variable that represents firm's $i$ incentive to carry out innovation activities at period $t\left(i=1, \ldots N ; t=1, \ldots T_{i}\right)$. This innovation incentive can be expressed as a function of firm, market and industry characteristics $\mathbf{w}_{i t}$ taken at period $t$, unobserved individual effects $\eta_{i}$, and other unobserved time-varying variables $u_{i t}$. Formally $d_{i t}^{*}$ is written as

$$
d_{i t}^{*}=\boldsymbol{\delta}^{\prime} \mathbf{w}_{i t}+\eta_{i}+u_{i t}
$$

where $\delta$ is a vector of parameters to be estimated. The incentive to carry out innovation activities is not observed, instead we observe $d_{i t}$ that takes on the value one if the enterprise is actually innovative, which is the case if the incentive to perform innovation activities is sufficiently large (i.e. if it crosses a certain threshold, say 0), and zero otherwise. Formally, $d_{i t}$ is written as

$$
d_{i t}=\mathbf{1}\left[d_{i t}^{*}>0\right]
$$

where $\mathbf{1}[]$ is the indicator function that takes on the value one if the condition between squared brackets is satisfied, and zero otherwise. A continuously-innovative enterprise is defined as one for which the incentive to carry out innovation activities crosses the threshold at two consecutive periods, i.e. $d_{i t}^{*}>0$ and $d_{i, t-1}^{*}>0$, hence the double index selection rule

$$
d_{i t} d_{i, t-1}=\mathbf{1}\left[d_{i t}^{*}>0 \cap d_{i, t-1}^{*}>0\right],
$$

where $\cap$ is the intersection operator.

\footnotetext{
${ }^{10}$ In the econometric literature, models with selection rules based on two indices are often referred to as "double hurdle" models (see e.g. Cragg, 1971; Blundell and Meghir, 1987). However these models are different from the one considered in this analysis in that the double indices are defined according to two different latent variables measured at the same time period in the double hurdle model, while in our model they are defined according to a single latent variable but taken at two different time periods.
} 


\subsection{Dynamic bivariate tobit}

Let $y_{1 i t}^{*}$ and $y_{2 i t}^{*}$ denote two latent variables modeling innovation input and innovation output of firm $i$ at period $t$. They are expressed as functions of past observed innovation input $y_{1 i, t-1}$ and innovation output $y_{2 i, t-1}$, current and past explanatory variables $\mathbf{x}_{i t}$ taken to be exogenous, unobserved individual effects $\alpha_{i}$ and other time-varying unobserved variables $\epsilon_{1 i t}$ and $\epsilon_{2 i t}$. Formally, innovation input and innovation output are written as

$$
\begin{aligned}
& y_{1 i t}^{*}=\gamma_{11} y_{1 i, t-1}+\gamma_{12} y_{2 i, t-1}+\boldsymbol{\beta}_{1}^{\prime} \mathbf{x}_{i t}+\alpha_{i}+\epsilon_{1 i t}, \\
& y_{2 i t}^{*}=\gamma_{21} y_{1 i, t-1}+\gamma_{22} y_{2 i, t-1}+\boldsymbol{\beta}_{2}^{\prime} \mathbf{x}_{i t}+\lambda \alpha_{i}+\epsilon_{2 i t},
\end{aligned}
$$

where $\gamma_{j k}, \boldsymbol{\beta}_{j}(j, k=1,2)$ and $\lambda$ are parameters to be estimated. A few remarks are worth making when considering eqs. (4) and (5). First, we denote innovation input and innovation output with a "*" as a superscript to emphasize that they are only partially observed. More specifically, the conditions in equation (3) must be satisfied for innovation input and innovation output to be observed. Secondly, the same term $\alpha_{i}$ enters both equations, which means that we assume the observed and unobserved variables that proxy individual effects to be the same across equations but with a different effect in each equation, hence the presence of the factor loading $\lambda$ in equation (5). However, different individual effects $\eta_{i}$ (correlated with $\alpha_{i}$ ) are included in the selection equation so as to estimate the magnitude of the sample selection bias. Finally, the same vector of explanatory variables $\mathbf{x}_{i t}$ enters both equations of our analysis although it be may different across equations. ${ }^{11}$

Let $y_{1 i t}$ and $y_{2 i t}$ denote the observed counterparts to $y_{1 i t}^{*}$ and $y_{2 i t}^{*}$. They are fully observed for enterprises that satisfy the conditions of equation (3). However, even when they are fully observed, $y_{1 i t}$ and $y_{2 i t}$ are censored in the sense that they take on zero or very small values for a significantly large percentage of continuously-innovative enterprises (cf. Table 3), hence the choice of tobit-type models to study the dynamics of innovation. We use a dynamic bivariate tobit so as to estimate jointly both equations allowing for a cross-equation correlation between the idiosyncratic errors $\epsilon_{1 i t}$ and $\epsilon_{2 i t} .{ }^{12}$

The observed dependent variables of innovation input and innovation output are defined as

\footnotetext{
${ }^{11}$ Unless economic theory suggests otherwise, there is no reason why the vector of explanatory variables should be different across equations.

${ }^{12}$ The use of common factor individual effects in the two equations implicitly assumes a cross-equation correlation of one between the individual effects.
} 
follows

$$
\left(y_{1 i t}, y_{2 i t}\right)=\left\{\begin{array}{l}
\text { unobserved if } d_{i t}^{*} \leq 0 \cup d_{i, t-1}^{*} \leq 0 \\
\left(c_{1}, c_{2}\right) \text { if } d_{i t}^{*}>0 \cap d_{i, t-1}^{*}>0 \cap y_{1 i t}^{*} \leq c_{1} \cap y_{2 i t}^{*} \leq c_{2} \\
\left(y_{1 i t}^{*}, c_{2}\right) \text { if } d_{i t}^{*}>0 \cap d_{i, t-1}^{*}>0 \cap y_{1 i t}^{*}>c_{1} \cap y_{2 i t}^{*} \leq c_{2} \\
\left(c_{1}, y_{2 i t}^{*}\right) \text { if } d_{i t}^{*}>0 \cap d_{i, t-1}^{*}>0 \cap y_{1 i t}^{*} \leq c_{1} \cap y_{2 i t}^{*}>c_{2} \\
\left(y_{1 i t}^{*}, y_{2 i t}^{*}\right) \text { if } d_{i t}^{*}>0 \cap d_{i, t-1}^{*}>0 \cap y_{1 i t}^{*}>c_{1} \cap y_{2 i t}^{*}>c_{2}
\end{array}\right.
$$

where $\cup$ denotes the union operator.

Equation (6) identifies five categories of enterprises. A first category consists of enterprises that are not continuously innovative, i.e. that do not satisfy the conditions of equation (3). This category consists of three sub-categories of enterprises that are never innovative, those that are innovative at period $t$ but are not at period $t$-1, or those that are not innovative at period $t$ - 1 but are innovative at period $t$ (cf. Table 2). According to equations (4) and (5), innovation input and innovation output are missing for enterprises that belong to the first category because of missing values in their current or lagged determinants. A second category consists of continuously-innovative enterprises that have zero or very small values of innovation input and innovation output, i.e. the corresponding latent variables do not cross the censoring thresholds $c_{1}$ and $c_{2}$. A third category consists of continuously-innovative firms with sufficiently large innovation input, i.e. $y_{1 i t}^{*}>c_{1}$, but with zero or very small values of innovation output, i.e. $y_{2 i t}^{*} \leq c_{2}$. A fourth category consists of continuously-innovative enterprises that are in the opposite situation to the third category. Finally, a fifth category consists of continuously-innovative enterprises whose innovation input and innovation output are sufficiently large, i.e. $y_{1 i t}^{*}>c_{1}$ and $y_{2 i t}^{*}>c_{2}$.

\section{Choice of $c_{1}$ and $c_{2}$}

The censoring thresholds $c_{1}$ and $c_{2}$ determine the degree of censoring of innovation input and innovation output. For instance, if equations (4) and (5) are estimated separately, Table 3 suggests that innovation input measured by R\&D expenditures over total sales and innovation output are censored for $10 \%$ and $18 \%$ of continuously-innovative enterprises respectively if both censoring thresholds are equal to 0 . Table 4 shows the four types of continuously-innovative enterprises that enter the bivariate tobit analysis, as identified by equation (6), for both measures of innovation input and for different values of the censoring thresholds. These values are chosen according to a trial and error method. In other words, we have in earlier stages of the analysis ignored the issue of zero and small values of innovation input and innovation output estimating by ML a bivariate panel VAR model using the sample of continuously-innovative enterprises. We have also estimated 
a dynamic bivariate tobit model with both censoring thresholds equal to 0 . Neither approach was satisfactory because we could not achieve convergence in maximizing the log-likelihood and obtain reliable estimates. One problem that we faced was that we could not obtain the standard errors of the estimates because the Hessian matrix or the outer product of gradients could not be inverted. We suspected the zero and small values of innovation input and innovation output to "contaminate" the estimation by inducing measurement errors in the probability distribution functions of the log-likelihood. Censoring only the zero values of both dependent variables was unfortunately not sufficient to obtain reliable estimates. Hence, we had to censor more small values of innovation input and innovation output, which led us to choose $c_{1}$ equal to 0.002 and $c_{2}$ equal to 0.05 . Other choices of $c_{1}=0.05$ and $c_{2}=0.002$, and $c_{1}=c_{2}=0.05$ are made to study the robustness of the analysis to different censoring thresholds.

\section{Estimation}

The maximum likelihood estimation of the dynamic bivariate tobit model with double index sample selection is described as follows. We first solve the initial conditions problem that occurs in the second stage of the model using Wooldridge's (2005) "simple solutions", and make distributional assumptions on the individual effects and the idiosyncratic errors.

\subsection{Initial conditions}

The Wooldridge treatment of the initial conditions consists in projecting the individual effects of equations (4) and (5) on the initial period values of the dependent variables $y_{1 i 0}$ and $y_{2 i 0}$, and on each time period values of sufficiently time-varying regressors or on their within mean $\overline{\mathbf{x}}_{i}$ so as to allow for individual effects that are correlated with exogenous explanatory variables. Formally,

$$
\alpha_{i}=b_{0}+b_{1} y_{1 i 0}+b_{2} y_{2 i 0}+\boldsymbol{b}_{3}^{\prime} \overline{\mathbf{x}}_{i}+\mu_{i}
$$

where $\mu_{i}$ is independent of $\boldsymbol{\epsilon}_{i t}=\left(\epsilon_{1 i t}, \epsilon_{2 i t}\right), y_{1 i 0}, y_{2 i 0}$ and $\mathbf{x}$, and $b_{0}, b_{1}, b_{2}$ and $\boldsymbol{b}_{3}$ are additional parameters to be estimated. ${ }^{13}$ The assumption of common factor individual effects implies that the additional parameters $b_{0}, b_{1}, b_{2}$ and $\boldsymbol{b}_{3}$ are different across equations only up to the factor loading $\lambda$.

${ }^{13}$ If $\boldsymbol{\beta}_{1}$ and $\boldsymbol{\beta}_{2}$ include an intercept parameter, it is not separately identified from $b_{0}$. 


\subsection{Distributional assumptions}

In order to specify the likelihood function, we make the following assumptions on the individual effects and the idiosyncratic errors. First, conditional on $\eta_{i}, u_{i t}$ is identically and independently distributed across individuals and over time so that the bivariate probability of being selected in the estimation sample is the product of two univariate probabilities. In other words, a special form of serial correlation referred to as equicorrelation in the econometric literature is assumed in the error terms $\eta_{i}+u_{i t}$. A similar assumption is made for $\epsilon_{1 i t}$ and $\epsilon_{2 i t}$ conditional on $\alpha_{i}$. Secondly, the sample selection effect is assumed to operate only through the individual effects. This assumption results in a simpler likelihood expression but does not harm the analysis by restricting the model. Indeed, it is a common assumption made in the econometric literature on panel data sample selection models. For instance, by making a similar assumption, Kyriazidou (1997) takes kernelweighted time differences of observations that eliminate not only the individual effects but also the sample selection effect (see also Charlier et al., 2001). Furthermore, we estimate in Raymond et al. (forthcoming) a dynamic type 2 tobit model using the same data and find that such an assumption is plausible because the correlation between the idiosyncratic errors of the selection equation and the regression equation is not significantly estimated, unlike that of the individual effects of the two equations, once we use a proper treatment of the initial conditions .

The individual effects $\left(\eta_{i}, \mu_{i}\right)^{\prime}$ and the idiosyncratic errors $\left(u_{i t}, \epsilon_{1 i t}, \epsilon_{2 i t}\right)^{\prime}$ are mutually independent, and identically and independently normally distributed with mean zero and covariance matrix

$$
\Sigma=\left(\begin{array}{ccccc}
\sigma_{\eta}^{2} & & & & \\
\rho_{\eta \mu} \sigma_{\eta} \sigma_{\mu} & \sigma_{\mu}^{2} & & & \\
0 & 0 & 1 & & \\
0 & 0 & 0 & \sigma_{1}^{2} & \\
0 & 0 & 0 & \rho_{12} \sigma_{1} \sigma_{2} & \sigma_{2}^{2}
\end{array}\right)
$$

\subsection{Likelihood}

According to equation (6) five different contributions to the likelihood function are to be distinguished. The individual contribution to the likelihood of a firm that is not selected in the sample on which the estimation of the dynamic bivariate tobit is based is given by

$$
L_{0 i}=\prod_{i=1}^{T_{i}}\left[\Phi_{1}\left(-M_{i t}-\eta_{i}\right)+\Phi_{1}\left(-M_{i, t-1}-\eta_{i}\right)-\Phi_{1}\left(-M_{i t}-\eta_{i}\right) \Phi_{1}\left(-M_{i, t-1}-\eta_{i}\right)\right]^{1-d_{i t} d_{i, t-1}}
$$


where $\Phi_{1}$ denotes the univariate cumulative distribution function (cdf) of the standard normal distribution and $M_{i t}=\boldsymbol{\delta}^{\prime} \mathbf{w}_{i t}$.

Let $D_{1 i t}=\mathbf{1}\left[y_{1 i t}^{*}>c_{1}\right]$ and $D_{2 i t}=\mathbf{1}\left[y_{2 i t}^{*}>c_{2}\right]$ where $\mathbf{1}[]$ is the indicator function explained previously, and to save space define

$$
\begin{aligned}
& N_{1 i t}=\gamma_{11} y_{1 i, t-1}+\gamma_{12} y_{2 i, t-1}+\boldsymbol{\beta}_{1}^{\prime} \mathbf{x}_{i t} \\
& N_{2 i t}=\gamma_{21} y_{1 i, t-1}+\gamma_{22} y_{2 i, t-1}+\boldsymbol{\beta}_{2}^{\prime} \mathbf{x}_{i t},
\end{aligned}
$$

the contribution to the likelihood of a firm that is selected in the estimation sample but whose measures of innovation input and innovation output are zero or very small, i.e. the corresponding latent variables are below the thresholds $c_{1}$ and $c_{2}$, is given by

$$
\begin{aligned}
L_{1 i}^{c_{1} c_{2}}=\prod_{i=1}^{T_{i}} & {\left[\left(\int_{-M_{i t}-\eta_{i}}^{\infty} \int_{-M_{i, t-1}-\eta_{i}}^{\infty} \int_{-\infty}^{c_{1}-N_{1 i t}-\alpha_{i}} \int_{-\infty}^{c_{2}-N_{2 i t}-\lambda \alpha_{i}} f_{4}\left(u_{i t}, u_{i, t-1}, \epsilon_{1 i t}, \epsilon_{2 i t}\right)\right.\right.} \\
\left.\left.d u_{i t} d u_{i, t-1} d \epsilon_{1 i t} d \epsilon_{2 i t}\right)^{\left(1-D_{1 i t}\right)\left(1-D_{2 i t}\right)}\right] & d^{d_{i t} d_{i, t-1}}
\end{aligned}
$$

where $f_{4}$ denotes the quadrivariate probability distribution function (pdf) of the normal distribution. However, according to the assumption on the idiosyncratic errors conditional on the individual effects and the assumption on the sample selection effect, $f_{4}$ can be written as the product of $f_{1}\left(u_{i t}\right), f_{1}\left(u_{i, t-1}\right)$ and $f_{2}\left(\epsilon_{1 i t}, \epsilon_{2 i t}\right)$ where $f_{1}$ and $f_{2}$ denote the univariate and the bivariate pdf of the normal distribution respectively. Hence, equation (11) can be written as

$$
\begin{aligned}
L_{1 i}^{c_{1} c_{2}}=\prod_{i=1}^{T_{i}}\{ & {\left[\Phi_{2}\left(\frac{c_{1}-N_{1 i t}-\alpha_{i}}{\sigma_{1}}, \frac{c_{2}-N_{2 i t}-\lambda \alpha_{i}}{\sigma_{2}}, \rho_{12}\right)\right.} \\
& \left.\left.\Phi_{1}\left(M_{i t}+\eta_{i}\right) \Phi_{1}\left(M_{i, t-1}+\eta_{i}\right)\right]^{\left(1-D_{1 i t}\right)\left(1-D_{2 i t}\right)}\right\},
\end{aligned}
$$

where $\Phi_{2}$ denotes the bivariate cdf of the standard normal distribution.

The contribution to the likelihood of a firm that is selected in the estimation sample with sufficiently large innovation input but with zero or very small values of innovation output is given by

$$
\begin{aligned}
L_{1 i}^{y_{1} c_{2}}=\prod_{i=1}^{T_{i}} & {\left[\left(\int_{-M_{i t}-\eta_{i}}^{\infty} \int_{-M_{i, t-1}-\eta_{i}}^{\infty} \int_{-\infty}^{c_{2}-N_{2 i t}-\lambda \alpha_{i}} f_{4}\left(u_{i t}, u_{i, t-1}, y_{1 i t}, \epsilon_{2 i t}\right)\right.\right.} \\
\left.\left.d u_{i t} d u_{i, t-1} d \epsilon_{2 i t}\right)^{D_{1 i t}\left(1-D_{2 i t}\right)}\right] & ]^{d_{i t} d_{i, t-1}}
\end{aligned}
$$


which can also be written as

$$
\begin{aligned}
L_{1 i}^{y_{1} c_{2}} & =\prod_{i=1}^{T_{i}}\left[\left(\Phi_{1}\left(M_{i t}+\eta_{i}\right) \Phi_{1}\left(M_{i, t-1}+\eta_{i}\right) \int_{-\infty}^{c_{2}-N_{2 i t}-\lambda \alpha_{i}} f_{2}\left(y_{1 i t}, \epsilon_{2 i t}\right) d \epsilon_{2 i t}\right)^{D_{1 i t}\left(1-D_{2 i t}\right)}\right]^{d_{i t} d_{i, t-1}} \\
& =\prod_{i=1}^{T_{i}}\left[\left(\Phi_{1}\left(M_{i t}+\eta_{i}\right) \Phi_{1}\left(M_{i, t-1}+\eta_{i}\right) f_{1}\left(y_{1 i t}\right) \int_{-\infty}^{c_{2}-N_{2 i t}-\lambda \alpha_{i}} f_{1}\left(\epsilon_{2 i t} \mid y_{1 i t}\right) d \epsilon_{2 i t}\right)^{D_{1 i t}\left(1-D_{2 i t}\right)}\right] .
\end{aligned}
$$

The final expression of $L_{1 i}^{y_{1} c_{2}}$ is given by

$$
\begin{aligned}
L_{1 i}^{y_{1} c_{2}}=\prod_{i=1}^{T_{i}} & {\left[\left(\Phi_{1}\left(M_{i t}+\eta_{i}\right) \Phi_{1}\left(M_{i, t-1}+\eta_{i}\right) \phi_{1}\left[\left(y_{1 i t}-N_{1 i t}-\alpha_{i}\right) / \sigma_{1}\right] / \sigma_{1}\right.\right.} \\
& \left.\left.\Phi_{1}\left(\frac{c_{2}-N_{2 i t}-\lambda \alpha_{i}-\rho_{12} \frac{\sigma_{2}}{\sigma_{1}}\left(y_{1 i t}-N_{1 i t}-\alpha_{i}\right)}{\sigma_{2} \sqrt{1-\rho_{12}^{2}}}\right)\right)^{D_{1 i t}\left(1-D_{2 i t}\right)}\right]^{d_{i t} d_{i, t-1}}
\end{aligned}
$$

where $\phi_{1}$ denotes the univariate pdf of the standard normal distribution.

Following a similar approach we show that the contribution to the likelihood of a firm that is selected in the estimation sample with sufficiently large innovation output but with zero or very small values of innovation input is given by

$$
\begin{aligned}
L_{1 i}^{c_{1} y_{2}}=\prod_{i=1}^{T_{i}} & {\left[\left(\Phi_{1}\left(M_{i t}+\eta_{i}\right) \Phi_{1}\left(M_{i, t-1}+\eta_{i}\right) \phi_{1}\left[\left(y_{2 i t}-N_{2 i t}-\lambda \alpha_{i}\right) / \sigma_{2}\right] / \sigma_{2}\right.\right.} \\
& \left.\left.\Phi_{1}\left(\frac{c_{1}-N_{1 i t}-\alpha_{i}-\rho_{12} \frac{\sigma_{1}}{\sigma_{2}}\left(y_{2 i t}-N_{2 i t}-\lambda \alpha_{i}\right)}{\sigma_{1} \sqrt{1-\rho_{12}^{2}}}\right)\right)^{\left(1-D_{1 i t}\right) D_{2 i t}}\right]^{d_{i t} d_{i, t-1}}
\end{aligned}
$$

Finally, the contribution to the likelihood of a firm selected in the estimation sample with sufficiently large innovation input and innovation output is given by

$$
\begin{aligned}
L_{1 i}^{y_{1} y_{2}}= & \prod_{i=1}^{T_{i}}\left\{\left[\Phi_{1}\left(M_{i t}+\eta_{i}\right) \Phi_{1}\left(M_{i, t-1}+\eta_{i}\right) \phi_{1}\left[\left(y_{2 i t}-N_{2 i t}-\lambda \alpha_{i}\right) / \sigma_{2}\right] / \sigma_{2}\right.\right. \\
& \left.\left.\frac{1}{\sigma_{1} \sqrt{1-\rho_{12}^{2}}} \phi_{1}\left(\frac{y_{1 i t}-N_{1 i t}-\alpha_{i}-\rho_{12} \frac{\sigma_{1}}{\sigma_{2}}\left(y_{2 i t}-N_{2 i t}-\lambda \alpha_{i}\right)}{\sigma_{1} \sqrt{1-\rho_{12}^{2}}}\right)\right]^{D_{1 i t} D_{2 i t}}\right\}^{d_{i t} d_{i, t-1}}
\end{aligned}
$$

The overall individual likelihood $L_{i}\left(\ldots \mid \eta_{i}, \mu_{i}\right)$ of the dynamic bivariate tobit with double index sample selection conditional on the individual effects is obtained, after replacing $\alpha_{i}$ by its expression (eq. (7)), by multiplying the expressions of equations (8), (12), (13), (14) and (15), i.e.

$$
L_{i}\left(\ldots \mid \eta_{i}, \mu_{i}\right)=L_{0 i} L_{1 i}^{c_{1} c_{2}} L_{1 i}^{y_{1} c_{2}} L_{1 i}^{c_{1} y_{2}} L_{1 i}^{y_{1} y_{2}} .
$$


We then obtain the unconditional individual likelihood by integrating the individual effects out of $L_{i}\left(\ldots \mid \eta_{i}, \alpha_{i}\right)$, i.e.

$$
L_{i}\left(\ldots, \eta_{i}, \mu_{i}\right)=\int_{-\infty}^{\infty} \int_{-\infty}^{\infty} L_{i}\left(\ldots \mid \eta_{i}, \mu_{i}\right) g_{2}\left(\eta_{i}, \mu_{i}\right) d \eta_{i} d \mu_{i}
$$

where $g_{2}$ denotes the bivariate normal density of $\eta_{i}$ and $\mu_{i}$. We evaluate the double integral in equation (17) using two-step Gauss-Hermite quadrature along the lines of Raymond (2007, chapter 3). The overall unconditional likelihood $L\left(\ldots, \eta_{i}, \mu_{i}\right)$ is obtained by taking the product over $i$ of the evaluated expression of equation (17).

\section{Results}

In subsection 6.1 we discuss the estimation results of the dynamic bivariate tobit model with double index sample selection (full model). More specifically, we discuss the effects of past innovation input on current innovation input and innovation output, those of past innovation output on current innovation input and innovation output, and test for their equality across categories of industry. Furthermore, we discuss the role of firm and industry effects, the effects of innovation determinants taken to be exogenous, the issue of sample selection bias and the robustness of the estimates to different censoring thresholds. We also present in the subsection (orthogonalized) impulse response functions, obtained from the tobit estimates, that analyze the response over time of innovation input and innovation output to shocks to innovation input and innovation output. In subsection 6.2 we contrast the tobit estimates with those of a panel VAR that does not correct for sample selection bias nor take account of the censoring feature of both innovation input and innovation output.

\subsection{Tobit estimates}

Table 6 shows ML estimation results of the full model with both measures of innovation input and censoring thresholds $c_{1}=0.002$ and $c_{2}=0.05 .{ }^{14}$ Panel $\mathrm{A}$ of the table shows the parameter estimates of the selection equation. Panel B shows the parameter estimates of the innovation input equation where we use, as measures of innovation input, R\&D expenditures over total sales in the first two columns and total innovation expenditures over total sales in the last two columns. Panel

\footnotetext{
${ }^{14}$ In order to save space, we only report the estimated coefficients of the selection equation, the lagged dependent variables, the industry and individual effects and the initial conditions. The coefficient estimates associated with the exogenous explanatory variables are not reported but can be obtained upon request. The estimation results of the model ignoring sample selection and using different censoring thresholds are not reported either but can also be obtained upon request.
} 
$\mathrm{C}$ shows the parameter estimates of the innovation output equation, and panel D shows those of the additional parameters (individual effects and initial conditions) of the model.

\section{Dynamics, firm and industry effects}

The dynamics of innovation is expected to be industry-specific because of product-life cycles that vary across industries (see e.g. Cefis and Orsenigo, 2001). Furthermore, Aghion et al. (2005) and Acemoglu et al. (2006) find that industries that are closer to the "technological frontier" are more competitive and feel more the pressure to innovate. Following this logic, firms in high-tech industries are in general closer to the "technological frontier" and are therefore more likely to display persistence in innovation. In order to allow for industry-specific innovation dynamics, we estimate the model by interacting the lagged dependent variables $\left(y_{1 i, t-1}, y_{2 i, t-1}\right)$ of each equation with four industry dummies following the OECD technology-based industry classification, namely high-tech, medium-high-tech, medium-low-tech and low-tech (see Appendix A). Then we perform Wald tests on the equality of the coefficients of the lagged dependent variables across industries. The results of these tests are reported in Table 7 and suggest the presence of industry heterogeneity regarding the dynamics of innovation. The joint null hypothesis of equality across all industries of the coefficients relating to the persistence of innovation input and innovation output, the lag effect of innovation input on innovation output, and the feedback effect of innovation output on innovation input can be rejected at $0.5 \%$ level of significance (see the lower part of Table 7 ). The main difference across industries in the dynamics stems from the persistence of innovation input and the lag effect of innovation input on innovation output, and depends on the nature of innovation input. The persistence of $\mathrm{R} \& \mathrm{D}$ is similar within the group of high- and mediumhigh-tech industries and within the group of medium-low- and low-tech industries, and the lag effect of $R \& D$ on innovation output is different in the high-tech industry compared to the other three. Similarly, the persistence of total innovation expenditures is different in the medium-lowtech industry compared to the other three, and the lag effect of total innovation expenditures on innovation output is different in the low-tech industry.

The findings of this analysis are as follows. First, there is evidence of persistence of innovation input and innovation output in all four industries in the sense that firms tend to have R\&D or total innovation expenditures if they had some in the previous period, and likewise they tend to have innovative sales if they had some in the previous period. One exception is the insignificant coefficient

of lagged $R \& D$ in the medium-low-tech industry. Secondly, we find evidence of a significant lag effect of R\&D on innovation output in the high-tech industry, and a significant lag effect of total innovation expenditures on innovation output in all four industries but the low-tech. Thirdly, non- 
Table 6: ML estimates of the dynamic bivariate tobit with double index sample selection: $c_{1}=0.002, c_{2}=0.05^{\ddagger}$

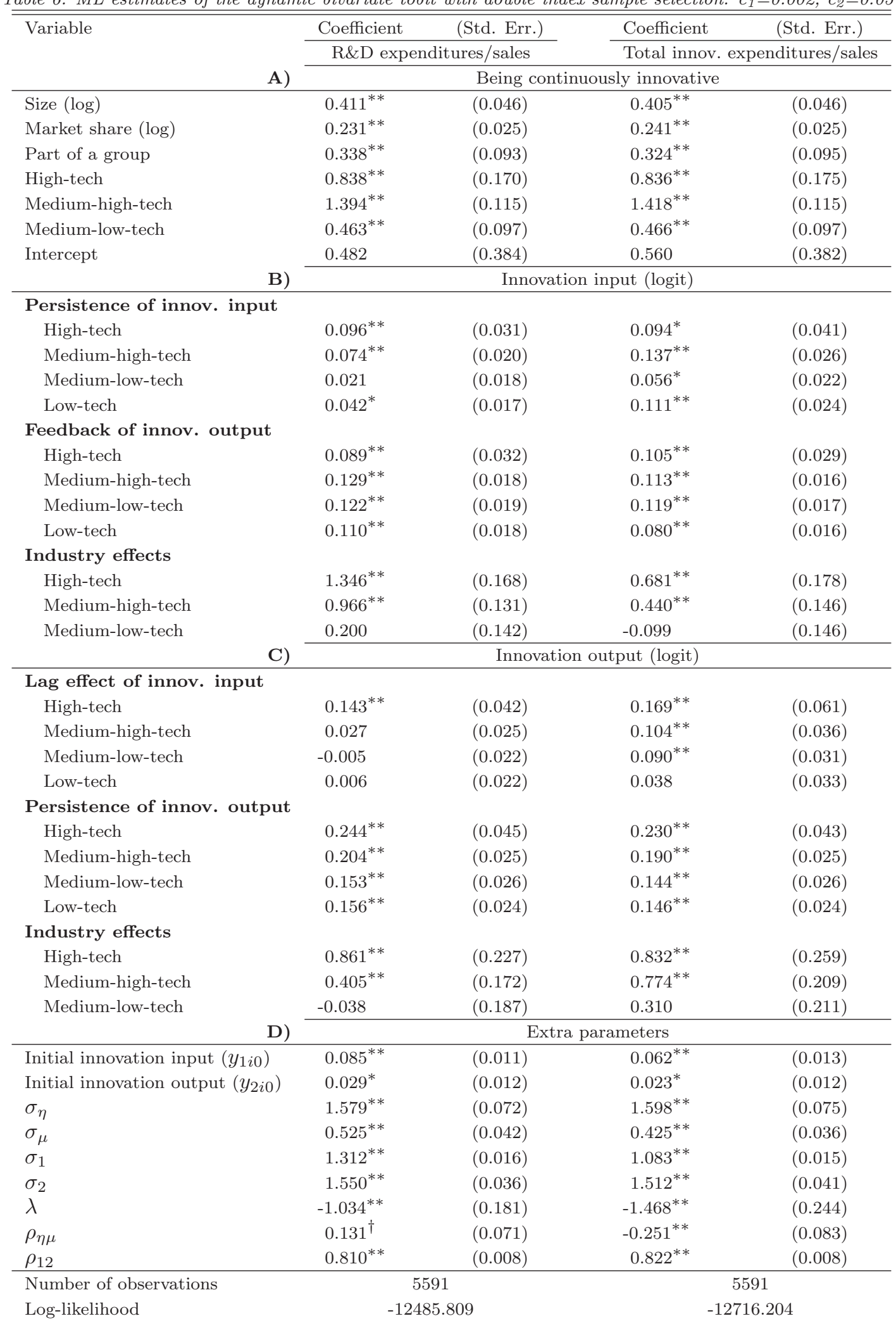

${ }^{\ddagger}$ Note: the low-tech industry is the reference, three time dummies are included in each equation so as to control for cross-sectional dependence.

Significance levels : $\quad$ : $10 \% \quad *: 5 \% \quad * *: 1 \%$ 


\begin{tabular}{|c|c|}
\hline R\&D expenditures/sales & Total innov. expenditures/sales \\
\hline \multicolumn{2}{|c|}{ Persistence of innovation input } \\
\hline $\begin{array}{l}\mathrm{H}_{0}: \gamma_{11}^{H}=\gamma_{11}^{M H}=\gamma_{11}^{M L}=\gamma_{11}^{L} \\
\operatorname{chi} 2(3)=8.31 ; \mathrm{p} \text {-value }=0.040\end{array}$ & $\begin{array}{l}\mathrm{H}_{0}: \gamma_{11}^{H}=\gamma_{11}^{M H}=\gamma_{11}^{M L}=\gamma_{11}^{L} \\
\text { chi2 }(3)=7.07 ; \text { p-value }=0.070\end{array}$ \\
\hline $\begin{array}{l}\mathrm{H}_{0}: \gamma_{11}^{H}=\gamma_{11}^{M H} ; \gamma_{11}^{M L}=\gamma_{11}^{L} \\
\text { chi2 }(2)=1.24 ; \mathrm{p} \text {-value }=0.537\end{array}$ & $\begin{array}{l}\mathrm{H}_{0}: \gamma_{11}^{H}=\gamma_{11}^{M H}=\gamma_{11}^{L} \\
\operatorname{chi} 2(2)=0.79 ; \text { p-value }=0.675\end{array}$ \\
\hline \multicolumn{2}{|c|}{ Feedback of innovation output } \\
\hline $\begin{array}{l}\mathrm{H}_{0}: \gamma_{12}^{H}=\gamma_{12}^{M H}=\gamma_{12}^{M L}=\gamma_{12}^{L} \\
\operatorname{chi} 2(3)=1.42 ; \mathrm{p} \text {-value }=0.700\end{array}$ & $\begin{array}{l}\mathrm{H}_{0}: \gamma_{12}^{H}=\gamma_{12}^{M H}=\gamma_{12}^{M L}=\gamma_{12}^{L} \\
\operatorname{chi} 2(3)=4.31 ; \text { p-value }=0.230\end{array}$ \\
\hline \multicolumn{2}{|c|}{ Lag effect of innovation input } \\
\hline $\begin{array}{l}\mathrm{H}_{0}: \gamma_{21}^{H}=\gamma_{21}^{M H}=\gamma_{21}^{M L}=\gamma_{21}^{L} \\
\operatorname{chi} 2(3)=11.28 ; \mathrm{p} \text {-value }=0.010\end{array}$ & $\begin{array}{l}\mathrm{H}_{0}: \gamma_{21}^{H}=\gamma_{21}^{M H}=\gamma_{21}^{M L}=\gamma_{21}^{L} \\
\operatorname{chi} 2(3)=5.07 ; \text { p-value }=0.167\end{array}$ \\
\hline $\begin{array}{l}\mathrm{H}_{0}: \gamma_{21}^{M H}=\gamma_{21}^{M L}=\gamma_{21}^{L} \\
\text { chi2 }(2)=1.15 ; \mathrm{p} \text {-value }=0.562\end{array}$ & $\begin{array}{l}\mathrm{H}_{0}: \gamma_{21}^{H}=\gamma_{21}^{M H}=\gamma_{21}^{M L} \\
\operatorname{chi} 2(2)=1.41 ; \text { p-value }=0.494\end{array}$ \\
\hline \multicolumn{2}{|c|}{ Persistence of innovation output } \\
\hline $\begin{array}{l}\mathrm{H}_{0}: \gamma_{22}^{H}=\gamma_{22}^{M H}=\gamma_{22}^{M L}=\gamma_{22}^{L} \\
\text { chi2 }(3)=5.46 ; \text { p-value }=0.141\end{array}$ & $\begin{array}{l}\mathrm{H}_{0}: \gamma_{22}^{H}=\gamma_{22}^{M H}=\gamma_{22}^{M L}=\gamma_{22}^{L} \\
\operatorname{chi} 2(3)=5.35 ; \text { p-value }=0.148\end{array}$ \\
\hline \multicolumn{2}{|c|}{ Joint test } \\
\hline $\begin{array}{c}\mathrm{H}_{0}: \gamma_{11}^{H}=\gamma_{11}^{M H}=\gamma_{11}^{M L}=\gamma_{11}^{L} ; \\
\gamma_{12}^{H}=\gamma_{12}^{M H}=\gamma_{12}^{M L}=\gamma_{12}^{L} ; \\
\gamma_{21}^{H}=\gamma_{21}^{M H}=\gamma_{21}^{M L}=\gamma_{21}^{L} ; \\
\gamma_{22}^{H}=\gamma_{22}^{M H}=\gamma_{22}^{M L}=\gamma_{22}^{L} \\
\operatorname{chi} 2(12)=28.80 ; \text { p-value }=0.004\end{array}$ & $\begin{array}{c}\mathrm{H}_{0}: \gamma_{11}^{H}=\gamma_{11}^{M H}=\gamma_{11}^{M L}=\gamma_{11}^{L} ; \\
\gamma_{12}^{H}=\gamma_{12}^{M H}=\gamma_{12}^{M L}=\gamma_{12}^{L} ; \\
\gamma_{21}^{H}=\gamma_{21}^{M H}=\gamma_{21}^{M L}=\gamma_{21}^{L} ; \\
\gamma_{22}^{H}=\gamma_{22}^{M H}=\gamma_{22}^{M L}=\gamma_{22}^{L} \\
\operatorname{chi} 2(12)=33.60 ; \text { p-value }=0.001\end{array}$ \\
\hline $\begin{array}{c}\mathrm{H}_{0}: \gamma_{11}^{H}=\gamma_{11}^{M H} ; \gamma_{11}^{M L}=\gamma_{11}^{L} \\
\gamma_{12}^{H}=\gamma_{12}^{M H}=\gamma_{12}^{M L}=\gamma_{12}^{L} \\
\gamma_{21}^{M H}=\gamma_{21}^{M L}=\gamma_{21}^{L} \\
\gamma_{22}^{H}=\gamma_{22}^{M H}=\gamma_{22}^{M L}=\gamma_{22}^{L}\end{array}$ & $\begin{aligned} \mathrm{H}_{0}: & \gamma_{11}^{H}=\gamma_{11}^{M H}=\gamma_{11}^{L} \\
\gamma_{12}^{H} & =\gamma_{12}^{M H}=\gamma_{12}^{M L}=\gamma_{12}^{L} \\
& \gamma_{21}^{H}=\gamma_{21}^{M H}=\gamma_{21}^{M L} \\
\gamma_{22}^{H} & =\gamma_{22}^{M H}=\gamma_{22}^{M L}=\gamma_{22}^{L}\end{aligned}$ \\
\hline $\operatorname{chi} 2(10)=13.70 ; \mathrm{p}$-value $=0.187$ & $\operatorname{chi} 2(10)=17.86 ; \mathrm{p}$-value $=0.057$ \\
\hline
\end{tabular}

R\&D innovation expenditures, e.g. the purchase of advanced machinery and computer hardware, play an important role in the generation of innovative sales at least in the medium-high- and the medium-low-tech industries. Fourthly, we find a significant feedback effect of innovative sales on R\&D or total innovation expenditures in all four industries. This result goes beyond the findings of Pakes and Griliches (1984), Hausman et al. (1984) and Hall et al. (1986), and is evidence in favor of treating innovation input and innovation output symmetrically as we have done in eqs. (4) and (5).

The results also show evidence of significant firm effects, as shown by the significantly-estimated standard deviations of the random-effects, and industry effects. Indeed the results suggest that, ceteris paribus, firms that belong to the high- and medium-high-tech industries spend on average significantly more on $\mathrm{R} \& \mathrm{D}$ and other innovation expenditures in proportion to sales, and have a significantly larger share of innovative sales than those that belong to the medium-low- and 
low-tech industries.

\section{Impulse response functions}

Figures 1 and 2 show, for the four industries and both measures of innovation input, (orthogonalized) impulse response functions (IRFs) derived from the tobit estimates of Table 6 . The IRFs are estimated for the population of continuously-innovative enterprises i.e. on the basis of equations (4) and (5) ignoring the selection equation. As a result, we drop the superscript "*" in the estimation of the IRFs as innovation input and innovation output are fully observed for continuously-innovative enterprises. Furthermore, while the censoring feature of $y_{1 i t}$ and $y_{2 i t}$ is accounted for in the estimation of the coefficients of the model, it is discarded in the estimation of the IRFs. To summarize, we rewrite equations (4) and (5) using matrix notation and dropping the individual subscript as

$$
\mathbf{y}_{t}=\mathbf{\Gamma} \mathbf{y}_{t-1}+\mathbf{B} \mathbf{x}_{t}+\boldsymbol{\alpha}+\epsilon_{t},
$$

where

$$
\mathbf{y}_{t}=\left(\begin{array}{c}
y_{1 i t} \\
y_{2 i t}
\end{array}\right), \quad \boldsymbol{\Gamma}=\left(\begin{array}{cc}
\gamma_{11} & \gamma_{12} \\
\gamma_{21} & \gamma_{22}
\end{array}\right), \mathbf{B}=\left(\begin{array}{c}
\boldsymbol{\beta}_{1} \\
\boldsymbol{\beta}_{2}
\end{array}\right), \quad \boldsymbol{\alpha}=\left(\begin{array}{c}
\alpha_{i} \\
\lambda \alpha_{i}
\end{array}\right) \text { and } \boldsymbol{\epsilon}_{t}=\left(\begin{array}{c}
\epsilon_{1 i t} \\
\epsilon_{2 i t}
\end{array}\right) \rightsquigarrow N(0, \boldsymbol{\Sigma})
$$

with $\boldsymbol{\Sigma}=\left(\begin{array}{cc}\sigma_{1}^{2} & \\ \rho_{12} \sigma_{1} \sigma_{2} & \sigma_{2}^{2}\end{array}\right)$. Provided that $\mathbf{y}_{t}$ is covariance stationary (we also assume that the exogenous regressors are covariance stationary), we can invert equation (18) so as to have a vector moving-average (VMA) representation, i.e.

$$
\mathbf{y}_{t}=\sum_{i=0}^{\infty} \boldsymbol{\Gamma}^{i} \boldsymbol{\epsilon}_{t-i}+\mathbf{B} \sum_{i=0}^{\infty} \boldsymbol{\Gamma}^{i} \boldsymbol{x}_{t-i}+\boldsymbol{\alpha} \sum_{i=0}^{\infty} \boldsymbol{\Gamma}^{i},
$$

where $\Gamma^{i}$ would measure the response of dependent variable $j$ after $i$ periods to a unit shock to dependent variable $k$ holding everything else constant, $(j, k=1,2)$. But the disturbances $\boldsymbol{\epsilon}_{t}$ are contemporaneously correlated, hence we cannot assume that everything else is held constant, i.e. equation (19) cannot provide a causal interpretation. As a result, we orthogonalize the disturbances as $\boldsymbol{\epsilon}_{t}=\mathbf{A} \mathbf{D}^{1 / 2} \mathbf{u}_{t}$ using the decomposition $\boldsymbol{\Sigma}=\mathbf{A} \mathbf{D A} \mathbf{A}^{\prime}$ where $\mathbf{u}_{t}$ denotes the orthogonalized disturbances and

$$
\mathbf{A}=\left(\begin{array}{cc}
1 & 0 \\
\frac{\sigma_{12}}{\sigma_{1}^{2}} & 1
\end{array}\right), \mathbf{D}=\left(\begin{array}{cc}
\sigma_{1}^{2} & 0 \\
0 & \sigma_{2}^{2}-\left(\sigma_{12}^{2} / \sigma_{1}^{2}\right)
\end{array}\right), \text { and } \sigma_{12}=\rho_{12} \sigma_{1} \sigma_{2}
$$




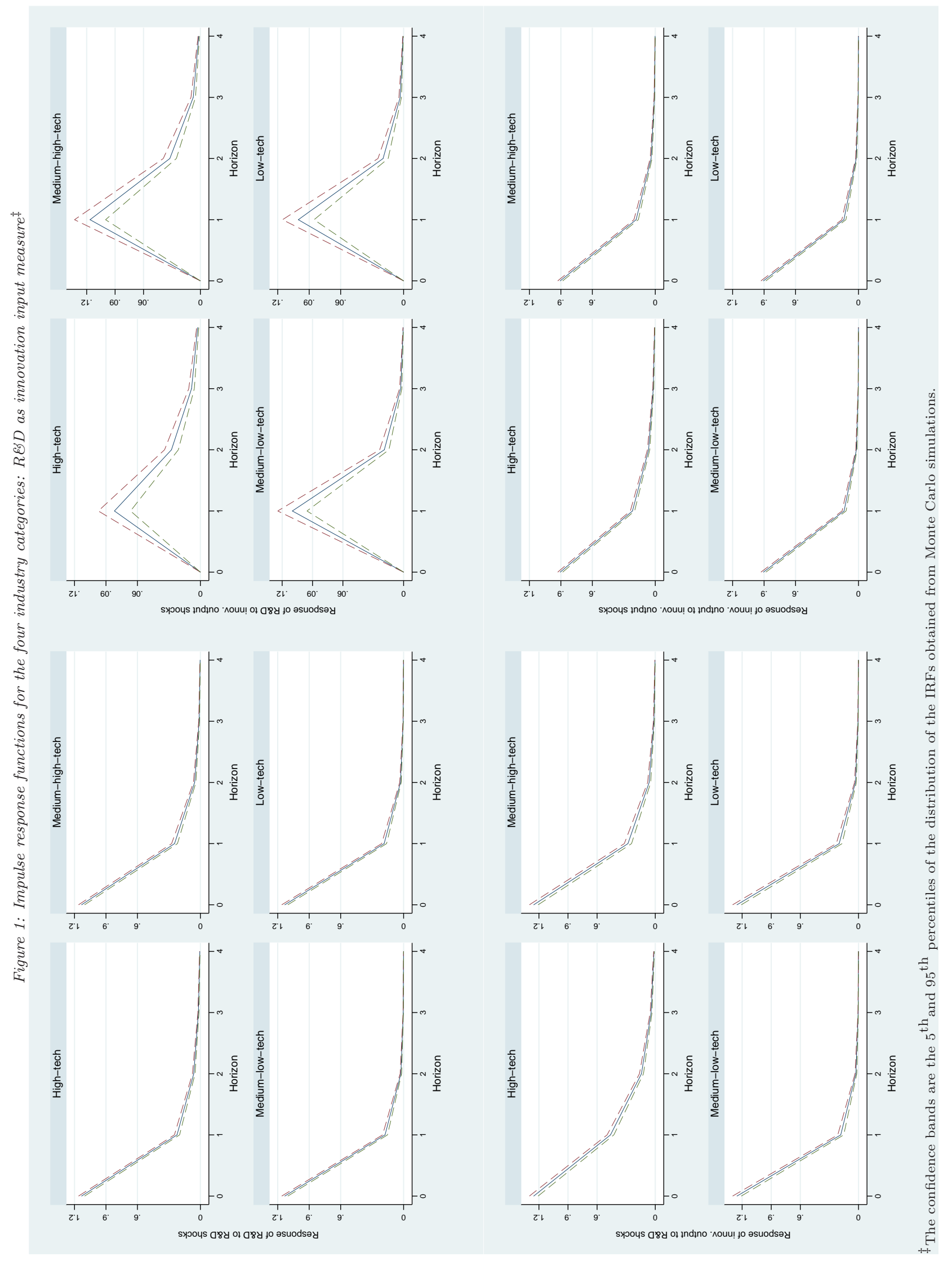




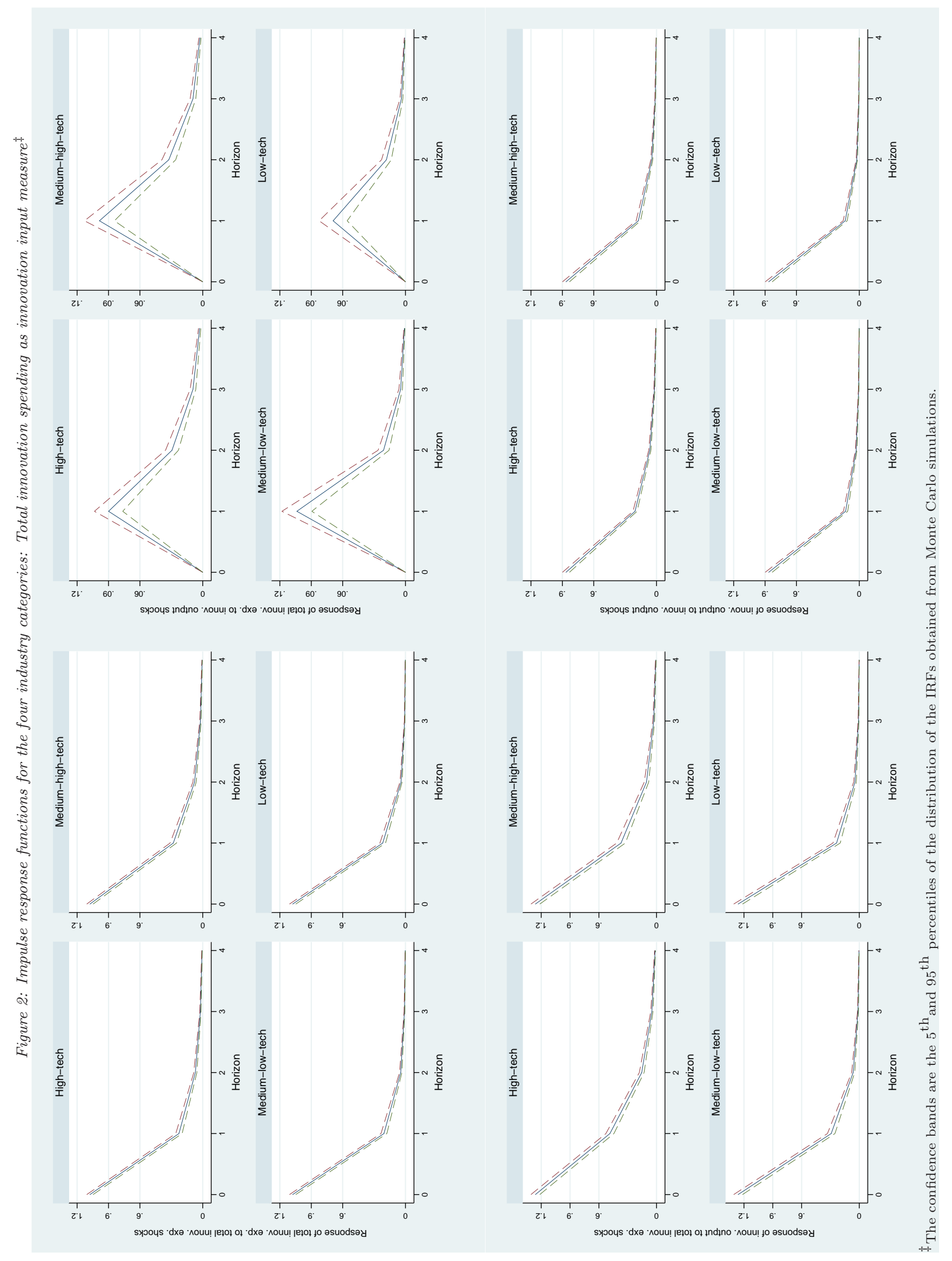


The resulting orthogonalized impulse response functions are derived as

$$
\boldsymbol{\Psi}^{i}=\boldsymbol{\Gamma}^{i} \mathbf{A D}^{1 / 2}
$$

and measure the response of dependent variable $j$ after $i$ periods, holding everything else constant, to a one standard deviation shock to dependent variable $k$ where innovation input is assumed to be determined prior to innovation output and hence comes first in the ordering. In order to obtain confidence intervals for the orthogonalized IRFs we randomly draw 500 sets of values for $\boldsymbol{\Gamma}, \mathbf{A}$ and $\mathbf{D}$ from a normal distribution with the estimated mean and standard error and calculate the orthogonalized IRFs for each set. The $95 \%$ confidence interval is then given by the $5^{\text {th }}$ and $95^{\text {th }}$ percentiles of the simulated distribution of the orthogonalized IRFs.

The IRFs reported in Figures 1 and 2 suggest that the response of innovation input and innovation output to shocks of innovation input and innovation output does not stretch beyond four periods, i.e. in our case eight years. Moreover, the effects of the shocks on the variables of interest vanish a bit faster in the medium-low- and low-tech industries than in the high- and medium-hightech industries, which is most visible for the response of innovation output to a shock in R\&D or total innovation expenditures. The pattern of response is very similar for the two types of innovation input.

\section{Exogenous determinants}

The effects of the exogenous explanatory variables (not reported) on innovation input are similar for both R\&D and total innovation expenditures. More specifically, ceteris paribus larger continuously-innovative enterprises do not spend more on R\&D or other innovation input components, but those that have a smaller market share and those that cooperate in innovation incur larger R\&D or total innovation expenditures. All three types of sources of information for innovation, namely internal, market and institutional sources, have a positive and significant effect on $\mathrm{R} \& \mathrm{D}$ or total innovation expenditures. Both measures seem to be driven by market demand (product-oriented effects) rather than cost reduction (process-oriented effects) or environmental sustainability.

As for innovation output, a similar pattern is observed with the exception of market share that has now a positive and significant effect on the share of innovative sales. In other words, ceteris paribus larger continuously-innovative enterprises do not have a larger share of innovative sales, the three types of sources of information for innovation are positively and significantly correlated with firm innovation success, and market demand is more important to innovation output than cost reduction and environmental sustainability. 


\section{Sample selection bias}

The sample selection bias is assessed by the magnitude of the correlation $\left(\rho_{\eta \mu}\right)$ between the individual effects of the selection equation and the dynamic bivariate tobit equation. The larger the correlation (in absolute value), the larger the bias. The estimated value of the correlation reported in Table 6 is rather small in absolute value, hence indicating a rather small sample selection bias. Furthermore, the estimation results (not reported) of the dynamic bivariate tobit given continuously innovative enterprises, i.e. ignoring the sample selection effect, are very similar to those of the full model corroborating the evidence of a small selection bias. This result may be explained by the specification of the selection equation of the full model. Indeed, if sample selection bias is present and significant in magnitude but uncontrolled for in the model, it will affect only the parameters of the explanatory variables of the equations of interest that are significant in both the selection equation and the equations of interest. However, because of the sampling design of the CIS (see Section 3), we have at our disposal very few explanatory variables that can be included in both the selection equation and the dynamic bivariate tobit regression. While size, market share and being part of a group have a positive and significant effect on the probability of being continuously innovative, only market share matters in the equations of innovation input and innovation output. As a result, the lack of strong evidence of the presence of sample selection may be partly due to the lack of explanatory power in the selection equation.

\section{Robustness analysis}

We have carried out a robustness analysis by estimating the model using two other pairs of thresholds besides $c_{1}=0.002$ and $c_{2}=0.05$, namely $c_{1}=0.05$ and $c_{2}=0.002$, and $c_{1}=c_{2}=0.05$. The estimated patterns in the dynamics of innovation are robust to changes in the thresholds. The results are less robust for the exogenous explanatory variables and the sample selection bias. More specifically, with $c_{1}=0.05$ and $c_{2}=0.002$, and $c_{1}=c_{2}=0.05$ size has a positive and significant effect on R\&D intensity and market share has an even more negative effect on both measures of innovation input. Only institutional sources matter to R\&D while market and institutional sources are important to total innovation expenditures. Finally, the magnitude of the sample selection bias increases in absolute value where the new estimated value of $\rho_{\eta \mu}$ is about -0.6 . This finding seems to corroborate the lack of explanatory power of the selection equation as one explanation of the small selection bias that we had previously found. Indeed, we now have two explanatory variables that are significant in both the selection equation and the equations of interest, namely size and market share, the effects of the latter being stronger (in absolute value) than previously. With more explanatory variables to explain significantly both the probability of being continuously innovative 
and innovation input and innovation output, we would expect the sample selection bias to be more severe.

\subsection{VAR estimates}

In order to emphasize the importance of accounting as much as possible for the features of the data, namely its (partial) truncation and censoring, we contrast the results of the full model that accounts for such features with those of a panel VAR that ignores at least the censoring characteristic of the data. In a first attempt to study the dynamics of innovation described in equations (4) and (5), we have estimated by maximum likelihood a panel VAR conditional on firms being continuously-innovative and ignoring the censoring feature of the three variables of interest. The individual likelihood of that model conditional on the individual effects is given by equation (15) where the outer exponent is equal to one and the inner exponent and the product of the two cdfs are removed from the expression. The resulting unconditional individual likelihood is obtained by replacing the new modified expression of equation (15) into equation (17). This approach to studying the dynamics of innovation was not successful because we could not obtain reliable estimates of the model. In particular, we could not obtain the standard errors of the estimates because the Hessian matrix or the outer product of gradients could not be inverted. That problem was due to too many zero and small values of innovation input and innovation output that "contaminated" the estimation by inducing measurement errors in the pdfs entering the log-likelihood function of the panel VAR. In a second attempt, we have modified the panel VAR so as to correct for sample selection bias resulting in a sample selection panel VAR. The individual conditional likelihood of this second version of the panel VAR is given by the product of the expressions of equations (8) and (15) where the inner exponent is removed from the latter equation. This second approach was not successful either for the same reasons mentioned earlier. In order to achieve reliable estimates of the panel VAR, we had to restrict further the sample of continuously-innovative enterprises so as to have observed positive values of innovation input and innovation output. Hence, we estimated the panel VAR using the sample of continuouslyinnovative firms with innovation input and innovation output greater than or equal to 0.002 and 0.05 respectively, which represents about $60 \%$ of the sample of continuously-innovative firms when $\mathrm{R} \& \mathrm{D}$ is used as a measure of innovation input and $67 \%$ of that sample when total innovation expenditures is used. The individual conditional likelihood of this third version of the panel VAR is given by equation (15) where the inner and outer exponents are equal to 1 and the product of the two cdfs is removed from the expression. Table 8 shows ML estimation results of the third version of the panel VAR that suggest that only the persistence of innovation input and innovation output 
Table 8: ML estimates of the VAR given continuously-innovative enterprises with innovation input $\geq 0.002$ and

\begin{tabular}{|c|c|c|c|c|}
\hline \multirow[t]{2}{*}{ Variable } & Coefficient & (Std. Err.) & Coefficient & (Std. Err.) \\
\hline & \multicolumn{2}{|c|}{ R\&D expenditures/sales } & \multicolumn{2}{|c|}{ Total innov. expenditures/sales } \\
\hline A) & \multicolumn{4}{|c|}{ Innovation input (logit) } \\
\hline \multicolumn{5}{|l|}{ Persistence of innov. input } \\
\hline High-tech & $0.161^{* *}$ & $(0.041)$ & $0.235^{* *}$ & $(0.045)$ \\
\hline Medium-high-tech & $0.119^{* *}$ & $(0.018)$ & $0.228^{* *}$ & $(0.030)$ \\
\hline Medium-low-tech & 0.008 & $(0.018)$ & $0.074^{* *}$ & $(0.025)$ \\
\hline Low-tech & $0.049^{*}$ & $(0.019)$ & $0.166^{* *}$ & $(0.028)$ \\
\hline \multicolumn{5}{|l|}{ Feedback of innov. output } \\
\hline High-tech & -0.012 & $(0.031)$ & -0.025 & $(0.034)$ \\
\hline Medium-high-tech & 0.001 & $(0.016)$ & -0.016 & $(0.018)$ \\
\hline Medium-low-tech & 0.010 & $(0.020)$ & -0.024 & $(0.020)$ \\
\hline Low-tech & 0.017 & $(0.021)$ & -0.027 & $(0.019)$ \\
\hline \multicolumn{5}{|l|}{ Industry effects } \\
\hline High-tech & $1.856^{* *}$ & $(0.194)$ & $1.245^{* *}$ & $(0.191)$ \\
\hline Medium-high-tech & $0.982^{* *}$ & $(0.141)$ & $0.554^{* *}$ & $(0.159)$ \\
\hline Medium-low-tech & -0.095 & $(0.153)$ & $-0.381^{*}$ & $(0.159)$ \\
\hline B) & \multicolumn{4}{|c|}{ Innovation output (logit) } \\
\hline \multicolumn{5}{|l|}{ Lag effect of innov. input } \\
\hline High-tech & $0.103^{\dagger}$ & $(0.055)$ & $0.111^{\dagger}$ & $(0.057)$ \\
\hline Medium-high-tech & -0.005 & $(0.025)$ & 0.021 & $(0.035)$ \\
\hline Medium-low-tech & -0.024 & $(0.025)$ & -0.015 & $(0.030)$ \\
\hline Low-tech & -0.027 & $(0.026)$ & -0.026 & $(0.034)$ \\
\hline \multicolumn{5}{|l|}{ Persistence of innov. output } \\
\hline High-tech & $0.250^{* *}$ & $(0.045)$ & $0.240^{* *}$ & $(0.045)$ \\
\hline Medium-high-tech & $0.146^{* *}$ & $(0.023)$ & $0.140^{* *}$ & $(0.023)$ \\
\hline Medium-low-tech & $0.074^{* *}$ & $(0.028)$ & $0.067^{* *}$ & $(0.025)$ \\
\hline Low-tech & $0.124^{* *}$ & $(0.029)$ & $0.086^{* *}$ & $(0.024)$ \\
\hline \multicolumn{5}{|l|}{ Industry effects } \\
\hline High-tech & $0.989^{* *}$ & $(0.247)$ & $1.008^{* *}$ & $(0.246)$ \\
\hline Medium-high-tech & $0.350^{\dagger}$ & $(0.182)$ & $0.515^{*}$ & $(0.204)$ \\
\hline \multirow[t]{2}{*}{ Medium-low-tech } & -0.033 & $(0.203)$ & 0.052 & $(0.206)$ \\
\hline & \multicolumn{4}{|c|}{ Extra parameters } \\
\hline Initial innovation input $\left(y_{1 i 0}\right)$ & $0.045^{* *}$ & $(0.011)$ & $0.038^{* *}$ & $(0.014)$ \\
\hline Initial innovation output $\left(y_{2 i 0}\right)$ & 0.018 & $(0.012)$ & 0.013 & $(0.012)$ \\
\hline$\sigma_{\mu}$ & $0.602^{* *}$ & $(0.033)$ & $0.455^{* *}$ & $(0.054)$ \\
\hline$\sigma_{1}$ & $0.702^{* *}$ & $(0.021)$ & $0.881^{* *}$ & $(0.027)$ \\
\hline$\sigma_{2}$ & $1.229^{* *}$ & $(0.025)$ & $1.164^{* *}$ & $(0.033)$ \\
\hline$\lambda$ & $0.555^{* *}$ & $(0.118)$ & $1.186^{* *}$ & $(0.255)$ \\
\hline$\rho_{12}$ & -0.062 & $(0.041)$ & $-0.089^{* *}$ & $(0.039)$ \\
\hline Number of observations & \multicolumn{2}{|c|}{1924} & \multicolumn{2}{|c|}{2168} \\
\hline Log-likelihood & \multicolumn{2}{|c|}{-5656.516} & \multicolumn{2}{|c|}{-6594.099} \\
\hline
\end{tabular}

is significant in the dynamic structure of innovation, i.e. only the diagonal parameters of matrix $\boldsymbol{\Gamma}$ are positively and significantly estimated, but the firm and industry effects remain significant.

Evidently, the comparison per se between the estimates of Tables 6 and 8 is not meaningful because the full model and the third version of the panel VAR are estimated using two different samples. Nevertheless, we report the estimation results of the latter model to emphasize the costs 
of not taking account of the censoring and truncation features of the data. Such costs are among others the inability to use the full "feasible" sample and the wrong inference made about the dynamics of the innovation process.

\section{Conclusion}

This study gives insights into the dynamic relationship between innovation input and innovation output in Dutch manufacturing using five waves of the Community Innovation Survey. We estimate a dynamic bivariate tobit with time-varying double index sample selection and find evidence of significant dynamics in the innovation process even after controlling for individual effects correlated with the initial values of the variables of interest. In other words, there is persistence of innovation input and innovation output, a lag effect of innovation input on innovation output that remains significant after four years in the high-tech industry, and a feedback effect of innovation output on innovation input. The result on the persistence of innovation input and innovation output is in accordance with Peters (2007) and Raymond et al. (forthcoming) who also use quantitative CIS data on innovation output and with Peters (2009) and Duguet and Monjon (2002) who use qualitative measures on innovation input and output respectively. The result on the lag effect of innovation input, measured by $R \& D$ or total innovation expenditures, on innovation output, measured by the share of innovative sales, contrasts with that of Hausman et al. (1984) and Hall et al. (1986) who only find simultaneity between R\&D and patents. Like those authors, we find that innovation input and innovation output are jointly determined as shown by the significant estimate of the correlation between the idiosyncratic errors of the two processes. Our findings also show that observed industry effects play an important role in the relationship. For instance, R\&D has a lag effect on the share of innovative sales only in the high-tech sector, and the lag effect of innovation input (for both measures) on innovation output lasts longer in the high- and to a lesser extent in the medium-high-tech industry than in the medium-low- and the low-tech industry. Differences in innovation behavior cannot, however, be solely attributed to observable differences across firms (e.g. high-tech versus low-tech). Unobserved heterogeneity, through firm effects, plays a crucial role in accounting for differences in innovation behavior and must be modeled.

The main caveat of this study stems from the features of the CIS data. First, the truncatedcensored feature makes it difficult to study the dynamics of the innovation process as dynamic tobit-type models with multiple equations must be used in order to achieve reliable estimates. In particular, a more parsimonious panel VAR cannot be used as it involves the costs of not being able to use the full "feasible" sample and making wrong inference about the dynamics. Secondly, the CIS 
data exhibits very little 'within' variation, which makes the use of distribution-free semiparametric techniques that rely on 'within' or time differences unfeasible. This involves the cost of making distributional assumption about the individual effects and the idiosyncratic errors which may yield an inconsistent ML estimator if the distributional assumptions are violated. However, given the features of the data, the study provides an alternative to the instrumental variable quasidifferenced method of Holtz-Eakin et al. (1988) to estimate panel VAR models. Finally, related to the truncated-censored feature of the data, we have at our disposal very few variables that allow to discriminate between innovative and non-innovative enterprises. This results in selection equation that is not very well specified and explains in part the lack of sample selection bias found in the analysis. 


\section{Appendix A Industry classification}

Table 9: Descriptive statistics per industry: The OECD classification based on 3-digit SBI

\begin{tabular}{|c|c|c|c|c|c|c|c|}
\hline \multirow{2}{*}{$\begin{array}{l}\text { Category } \\
\text { Industry }\end{array}$} & \multirow[t]{2}{*}{ SBI } & \multirow[t]{2}{*}{ \# obsv. } & \multirow[t]{2}{*}{$\%$} & \multicolumn{2}{|c|}{ Size } & \multicolumn{2}{|c|}{ Innovative $^{\dagger}$} \\
\hline & & & & Mean & Median & Occasional & Continuous \\
\hline \multicolumn{8}{|l|}{ High-tech } \\
\hline Aircraft, spacecraft & 35.3 & 11 & 0.20 & 395 & 173 & 0.727 & 0.636 \\
\hline Pharmaceuticals & 24.4 & 77 & 1.38 & 303 & 80 & 0.740 & 0.649 \\
\hline Office machinery & 30 & 34 & 0.61 & 623 & 115 & 0.853 & 0.853 \\
\hline Radio, TV equip. & 32 & 55 & 0.98 & 178 & 55 & 0.855 & 0.818 \\
\hline Medical, optical instr. & 33 & 190 & 3.40 & 194 & 70 & 0.684 & 0.600 \\
\hline Whole category & & 367 & 6.56 & 260 & 75 & 0.738 & 0.668 \\
\hline \multicolumn{8}{|l|}{ Medium-high-tech } \\
\hline Elect. machinery nec & 31 & 162 & 2.90 & 178 & 73 & 0.815 & 0.778 \\
\hline Motor vehic., trailers & 34 & 163 & 2.92 & 385 & 100 & 0.767 & 0.706 \\
\hline $\begin{array}{l}\text { Chemicals excl. } \\
\text { pharmaceuticals }\end{array}$ & $\begin{array}{l}24 \text { excl. } \\
24.4\end{array}$ & 368 & 6.58 & 242 & 110 & 0.807 & 0.758 \\
\hline $\begin{array}{l}\text { Railroad, transport } \\
\text { equipment nec }\end{array}$ & $\begin{array}{l}35.2,35.4 \\
\text { and } 35.5\end{array}$ & 24 & 0.43 & 120 & 96 & 0.750 & 0.750 \\
\hline M\&E nec & 29 & 703 & 12.57 & 160 & 80 & 0.762 & 0.704 \\
\hline Whole category & & 1420 & 25.40 & 208 & 85 & 0.780 & 0.727 \\
\hline \multicolumn{8}{|l|}{ Medium-low-tech } \\
\hline Ships, boats & 35.1 & 117 & 2.09 & 126 & 75 & 0.624 & 0.487 \\
\hline Rubber \& plastic & 25 & 318 & 5.69 & 124 & 85 & 0.774 & 0.711 \\
\hline Coke, petrol \& fuel & 23 & 26 & 0.47 & 364 & 49 & 0.769 & 0.654 \\
\hline Non-metallic minerals & 26 & 247 & 4.42 & 156 & 88 & 0.644 & 0.518 \\
\hline Metals & $27-28$ & 899 & 16.08 & 147 & 74 & 0.636 & 0.529 \\
\hline Whole category & & 1607 & 28.74 & 146 & 76 & 0.666 & 0.563 \\
\hline \multicolumn{8}{|l|}{ Low-tech } \\
\hline NEC, recycling & $36-37$ & 391 & 6.99 & 368 & 100 & 0.550 & 0.437 \\
\hline Wood \& paper & $20-22$ & 918 & 16.42 & 180 & 79 & 0.562 & 0.425 \\
\hline Food \& tobacco & $15-16$ & 646 & 11.55 & 311 & 100 & 0.649 & 0.526 \\
\hline Textiles \& leather & $17-19$ & 242 & 4.33 & 128 & 65 & 0.562 & 0.471 \\
\hline Whole category & & 2197 & 39.30 & 246 & 85 & 0.585 & 0.462 \\
\hline Whole manufacturing & $15-37$ & 5591 & 100.00 & 209 & 81 & 0.668 & 0.572 \\
\hline
\end{tabular}

${ }^{\dagger}$ For a definition of "innovative", see Section 3. Continuously, as opposed to occasionally, innovative firms innovate in at least two consecutive waves. 


\section{References}

Acemoglu, D., P. Aghion And F. Zilibotti, "Distance to Frontier, Selection, and Economic Growth," Journal of the European Economic Association 4 (2006), 37-74.

Acs, Z. J. And D. B. Audretsch, "Innovation, Market Structure, and Firm Size," Review of Economics and Statistics 69 (1987), 567-574.

Aghion, P., N. Bloom, R. Blundell, R. Griffith and P. Howitt, "Competition and Innovation: An Inverted-U Relashionship," Quarterly Journal of Economics 120 (2005), 701728.

AmemiyA, T., "Tobit Models: A Survey," Journal of Econometrics 24 (1984), 3-61.

Blundell, R. And C. MeghiR, "Bivariate Alternatives to the Tobit Model," Journal of Econometrics 34 (1987), 179-200.

Cefis, E. And L. Orsenigo, "The Persistence of Innovative Activities A Cross-Countries and Cross-Sectors Comparative Analysis," Research Policy 30 (2001), 1139-1158.

Charlier, E., B. Melenberg And A. van Soest, "An Analysis of Housing Expenditure using Semiparametric Models and Panel Data," Journal of Econometrics 101 (2001), 71-107.

CragG, J. G., "Some Statistical Models for Limited Dependent Variables with Application to the Demand for Durable Goods," Econometrica 39 (1971), 829-844.

D’Aspremont, C. And A. Jacquemin, "Cooperative and Noncooperative R\&D in Duopoly with Spillovers," American Economic Review 78 (1988), 1133-1137.

Duguet, E. And S. Monjon, "Creative Destruction and the Innovative Core: Is Innovation Persistent at the Firm Level?," UCL Discussion Paper 02-07, 2002.

Eurostat, "Nace Rev.1," Classifications, Statistical Office of the European Communities, 1992.

Geroski, P. A., J. van Reenen and C. F. Walters, "How Persistently do Firms Innovate?," Research Policy 26 (1997), 33-48.

Gouriéroux, C., A. Montfort and A. Trognon, "Pseudo Maximum Likelihood Methods: Applications to Poisson Models," Econometrica 52 (1984), 701-720.

Griliches, Z., "Patent Statistics as Economic Indicators: A Survey," Journal of Economic Literature 28 (1990), 1661-1707. 
Griliches, Z. and J. Mairesse, "Productivity and R\&D at the Firm Level," in Z. Griliches, ed., RED, Patents and Productivity (Chicago: University of Chicago Press, 1984), 339-374.

Hall, B. H., Z. Griliches and J. A. Hausman, "Patents and R and D: Is There a Lag?," International Economic Review 27 (1986), 265-283.

Hausman, J., B. H. Hall and Z. Griliches, "Econometric Models for Count Data with an Application to the Patents-R\&D Relationship," Econometrica 52 (1984), 909-938.

Holtz-Eakin, D., W. Newey and H. S. Rosen, "Estimating Vector Autoregressions with Panel Data," Econometrica 56 (1988), 1371-1395.

Kamien, M. I. And N. L. Schwartz, "Market Structure and Innovation: A Survey," Journal of Economic Literature 13 (1975), 1-37.

Kyriazidou, E., "Estimation of a Panel Data Sample Selection Model," Econometrica 65 (1997), $1335-1364$.

Levin, R. C., A. K. Klevorick, R. R. Nelson and S. G. Winter, "Appropriating the Returns from Industrial Research and Development," Brookings Paper on Economic Activity 3 (1987), 783-831.

OECD, Oslo Manual, Guidelines for Collecting and Interpreting Innovation Data, $3^{\text {rd }}$ edition (Paris: OECD Publishing, 2005).

- OECD Science, Technology and Industry Scoreboard 200\%: Innovation and Performance in the Global Economy (Paris: OECD; 2007 edition, 2007).

Pakes, A., "On Patents, R\&D, and the Stock Market Rate of Return," Journal of Political Economy 93 (1985), 390-409.

Pakes, A. And Z. Griliches, "Patents and R\&D at the Firm Level: A First Report," Economics Letters 5 (1980), 377-381.

— , "Patents and R\&D at the Firm Level: A First Look," in Z. Griliches, ed., RËD, Patents and Productivity (Chicago: University of Chicago Press, 1984), 55-72.

Pakes, A. And M. Schankerman, "The Rate of Obsolescence of Patents, Research Gestation Lags and Resources," in Z. Griliches, ed., RED, Patents and Productivity (Chicago: University of Chicago Press, 1984), 73-88. 
Peters, B., "Nothing's Gonna Stop us Now? An Empirical Investigation on the 'Innovation Sucess Breeds Success' Hypothesis," mimeo, 2007.

_ ogy Transfer 34 (2009), 226-243.

Ravenscraft, D. And F. M. Scherer, "The Lag Structure of Returns to Research and Development," Applied Economics 14 (1982), 603-620.

Raymond, W., "The Dynamics of Innovation and Firm Performance: An Econometric Panel Data Analysis," PhD Dissertation, 2007.

Raymond, W., P. Mohnen, F. Palm and S. Schim van Der Loeff, "Persistence of Innovation in Dutch Manufacturing: Is it Spurious?," Review of Economics and Statistics (forthcoming).

Scherer, F. M., "Corporate Inventive Output, Profits, and Growth," Journal of Political Economy 73 (1965), 290-297.

Schmookler, J., Invention and Economic Growth (Cambridge: Harvard University Press, 1966).

Schumpeter, J. A., The Theory of Economic Development (Cambridge, MA: Harvard University Press, 1934).

—, Capitalism, Socialism and Democracy (New York: Harper and Brothers, 1942).

Seldon, B. J., "A Nonresidual Estimation of Welfare Gains from Research: The Case of Public R\&D in a Forest Product Industry," Southern Economic Journal 54 (1987), 64-80.

van Ophem, H., E. Brouwer, A. Kleinknecht and P. Mohnen, "The Mutual Relation between Patents and R\&D," in A. Kleinknecht and P. Mohnen, eds., Innovation and Firm Performance (Hampshire and New York: Palgrave, 2002), 56-70.

Wooldridge, J. M., "Simple Solutions to the Initial Conditions Problem in Dynamic Nonlinear Panel Data Models with Unobserved Heterogeneity," Journal of Applied Econometrics 20 (2005), $39-54$. 